\title{
Characteristics of the near-tail dawn magnetopause and boundary layer
}

\author{
G. Paschmann ${ }^{1}$, S. Haaland ${ }^{1}$, B. U. Ö. Sonnerup ${ }^{2}$, H. Hasegawa ${ }^{2}$, E. Georgescu ${ }^{1}$, B. Klecker ${ }^{1}$, T. D. Phan ${ }^{3}$, H. Rème ${ }^{4}$, \\ and A. Vaivads ${ }^{5}$ \\ ${ }^{1}$ Max-Planck-Institut für extraterrestrische Physik, Garching, Germany \\ ${ }^{2}$ Thayer School of Engineering, Dartmouth College, Hanover, NH, USA \\ ${ }^{3}$ Space Sciences Laboratory, University of California, Berkeley, CA, USA \\ ${ }^{4}$ CESR-CNRS, Toulouse, France \\ ${ }^{5}$ Swedish Institute of Space Physics, Uppsala, Sweden
}

Received: 1 February 2005 - Revised: 29 March 2005 - Accepted: 31 March 2005 - Published: 3 June 2005

\begin{abstract}
The paper discusses properties of the near-tail dawnside magnetopause and boundary layer, as obtained from Cluster plasma and magnetic field measurements during a single skimming orbit on 4 and 5 July 2001 that included 24 well-defined magnetopause crossings by all four spacecraft. As a result of variations of the interplanetary magnetic field, the magnetic shear across the local magnetopause varied between $\sim 0^{\circ}$ and $\sim 180^{\circ}$. Using an improved method, which takes into account magnetopause acceleration and thickness variation, we have determined the magnetopause orientation, speed, thickness and current for the 96 individual magnetopause crossings. The orientations show clear evidence of surface waves. Magnetopause thicknesses range from $\sim 100$ to $\sim 2500 \mathrm{~km}$, with an average of $753 \mathrm{~km}$. The magnetopause speeds range from less than $10 \mathrm{~km} \mathrm{~s}^{-1}$ up to more than $300 \mathrm{~km} \mathrm{~s}^{-1}$, with an average of $48 \mathrm{~km} \mathrm{~s}^{-1}$. Both results are consistent with earlier ISEE and AMPTE results obtained for the dayside magnetopause. Importantly, scaling the thicknesses to the ion gyro radius or the ion inertial length did not reduce the large dynamic range. There is also no significant dependence of thickness on magnetic shear. Current densities range from $\sim 0.01 \mu \mathrm{A} \mathrm{m}^{-2}$ up to $\sim 0.3 \mathrm{uA}$, with an average value of $0.05 \mu \mathrm{A} \mathrm{m}^{-2}$. By including some extra crossings that did not involve all four spacecraft, we were able to apply the Walén test to a total of 60 crossings by Cluster 1 and 3, and have classified 19 cases as rotational discontinuities (RDs), of which 12 and 7 were crossings sunward and tailward of an X-line, respectively. Of these 60 crossings, 26 show no trace of a boundary layer. The only crossings with substantial boundary layers are crossings into the plasma mantle. Of the 26 crossings without a boundary layer, 8 were identified as RDs. Since reconnection produces wedge-shaped boundary layers emanating from the Xline, RDs without boundary layer may be considered cross-
\end{abstract}

Correspondence to: G. Paschmann

(goetz.paschmann@mpe.mpg.de) ings close to the $\mathrm{X}$-line, in which case the observed magnetic shear and Alfvén Mach number should be representative of the conditions at the X-line itself. It is therefore important that four of the eight cases had shear angles $\leq 100^{\circ}$, i.e. the reconnecting fields were far from being anti-parallel, and that all eight cases had Alfvén Mach numbers $M_{A}>1$ in the adjoining magnetosheath. Another important conclusion can be drawn from the crossings without a boundary layer that were tangential discontinuities (TDs). To observe TDs with no boundary layer at such large distances from the subsolar point appears to rule out diffusion over large portions of the magnetopause as an effective means for plasma transport across the magnetopause.

Key words. Magnetospheric physics (Magnetopause, cusp and boundary layers; Solar wind-magnetosphere interactions) - Space plasma physics (magnetic reconnection)

\section{Introduction}

This paper discusses properties of the near-tail dawnside magnetopause and boundary layer as obtained from plasma and magnetic field measurements by the Cluster spacecraft during a single skimming orbit that included 24 well-defined crossings by all four spacecraft. Emphasis is placed on determinations of the magnetopause orientation, speed, thickness, and currents; on magnetopause classification in terms of tangential vs. rotational discontinuity; separation of the crossings into those with and without an adjoining boundary layer; investigation of the magnetic shear dependence of magnetopause and boundary layer properties; and the identification of surface waves.

We use vector magnetic field measurements obtained by the flux gate magnetometer instrument FGM on all four spacecraft (Balogh et al., 1997). For overview purposes we present the data in terms of the standard 4-s spin-resolution 

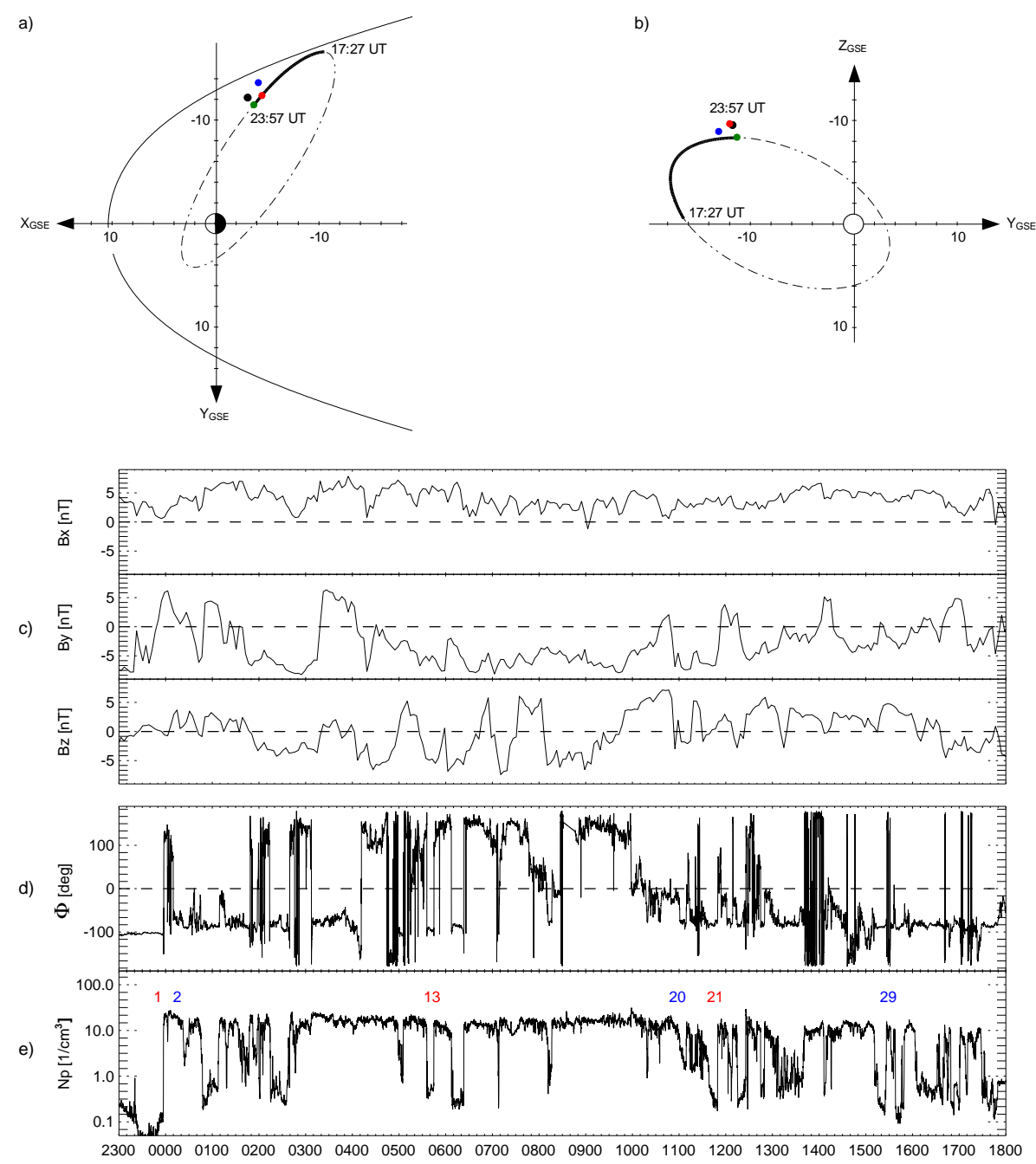

Fig. 1. Overview of spacecraft position and key parameters. Top: GSE XY (a) and YZ (b) projections of spacecraft orbit. The spacecraft separation distances are magnified by a factor of $\sim 5$ to show the tetrahedron configuration. The thick black lines show the trajectory during the time interval discussed in this paper. Panels (c): the three components of the IMF measured at ACE, shifted to account for the propagation delay. Panel (d): magnetic field orientation observed at Cluster C1. The angle $\phi$ is the azimuth angle in the (L,M)-plane of the boundarynormal coordinate system; $\phi=0^{\circ}$ is along the L-axis, which is pointing essentially northward. $\phi=90^{\circ}$ is along the M axis, which is pointing tailward along the magnetopause. Panel (e): plasma density from the CIS HIA instrument on C1. The labelled crossings (blue for inbound, red for outbound) are discussed in Sect. 5

averages, but for detailed analysis we use 0.2 -s averages. For the plasma properties we use the standard 4-s spin-resolution moments (density, bulk velocity, temperature) calculated on board from the 3-D ion distribution functions measured by CIS-HIA on spacecraft $\mathrm{C} 1$ and $\mathrm{C} 3$ (Rème et al., 2001). We also use the 0.2 -s resolution electron densities inferred from the spacecraft potential measurements by the EFW instrument (Gustafsson et al., 1997).

\section{Overview}

Between 23:40 UT on 4 July and 17:40 UT on 5 July 2001, the Cluster satellites were skimming the near-tail dawnside magnetopause at local times between 5.0 and $3.8 \mathrm{~h}$ and at lat- itudes decreasing from $32^{\circ}$ to $4^{\circ}$ (in GSM coordinates). The spacecraft separation distances were $\sim 3000 \mathrm{~km}$ at the beginning and $\sim 2000 \mathrm{~km}$ at the end of this time interval. Figure 1 shows the orbit and an overview of the interval, with interplanetary magnetic field (IMF) data from ACE, and magnetic field and plasma density from Cluster $\mathrm{C} 1$. Magnetopause crossings are recognized by a magnetic field rotation (panel d) and a jump in the ion density, from typical values of 10 to $20 \mathrm{~cm}^{-3}$ in the magnetosheath to values $<1 \mathrm{~cm}^{-3}$ in the magnetosphere (panel e).

Cluster first encountered the magnetopause around 23:57 UT on 4 July. The last crossing included in this study took place around 17:27 UT on 5 July. There were a total of 24 well-defined four-spacecraft crossings in this interval, 
of which 13 were outbound crossings, and 11 were inbound crossings. In addition, there were several crossings that did not involve all spacecraft. Numbers along the bottom panel of Fig. 1 mark the crossing number of the six magnetopause encounters presented in detail in Sect. 5. Note that the crossing at 06:23 UT, not dicussed here in detail, has already been the subject of several studies (Haaland et al., 2004; Hasegawa et al., 2004a,b).

As seen in Fig. 1, the interplanetary magnetic field measured by ACE, (panels c), was highly variable, particularly the north-south (i.e. $B_{z}$ ) component. The solar wind dynamic pressure (not shown), on the other hand, remained nearly constant at $2.5 \mathrm{nPa}$, with maxima and minima near 3.5 and $1.5 \mathrm{nPa}$, respectively. There is a tendency for the spacecraft to remain in the magnetosheath for longer periods for higher values of the dynamic pressure, when, based on pressure balance, the magnetopause is expected to be pushed in further. As we will see later, there is also clear evidence for crossings being caused by surface undulations.

Figure 1d shows the measured field direction, $\phi$, at $\mathrm{C} 1$ in the (L, M)-plane of the boundary normal cordinate system, where $\mathrm{L}$ and $\mathrm{M}$ point essentially northward, and tailward, respectively, in the plane tangent to the (model) magnetopause, with $\phi$ being counted from the $\mathrm{L}$ axis. The magnetic field on the magnetospheric side of the magnetopause was stable over the entire time interval and directed essentially along the negative $\mathrm{M}$ direction, as identified by $\phi$-angles near $-90^{\circ}$ in Fig. 1d. This is the expected direction for tailward stretched field lines in the Northern Hemisphere. In response to the variable IMF, the field direction in the magnetosheath was quite variable, as illustrated by the strong variations in $\phi$, including fields directed anti-parallel to the magnetospheric field, $\phi=90^{\circ}$, as shown in panel (d). The translation from the measured IMF at ACE to the magnetosheath field adjacent to the magnetopause crossings is, however, by no means straightforward, as it involves draping of the field around the magnetospheric obstacle, and its temporal response when the IMF, especially its $B_{y}$ component, changes.

From high-resolution plots of the $\phi$ angle, the sense and magnitude of the rotation of the field across the magnetopause (i.e. the magnetic shear angle) could be unambiguously determined. We quantify the shear by the (signed) change in $\phi$ relative to the magnetospheric orientation. The shear is counted positive if $\phi$ changes towards more positive values; it is negative for a change in the more negative direction. With this definition, the magnitude of the shear could, in principle, exceed $180^{\circ}$. It is thus significant that no shear angles with magnitude $>180^{\circ}$ have been observed, confirming the result reported by Berchem and Russell (1982) that the field rotation across the magnetopause has no preferred sense, but always takes the shortest path.

\section{Four-spacecraft analysis}

For each of the 24 complete crossings, we calculated magnetopause orientation, velocity, thickness, and current density.

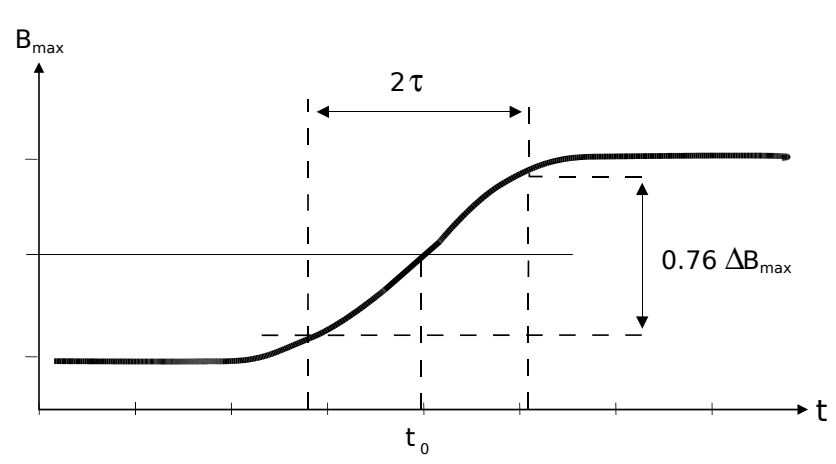

Fig. 2. Our definition of crossing time, $t_{0}$, and crossing duration, $2 \tau$ for a Harris sheet-like profile of $B_{\max }$. With a known magnetopause velocity, $V_{M P}$, the magnetopause thickness, $d_{M P}$ is given by $2 \tau *$ $\mathrm{V}_{\mathrm{MP}}$.

The basic procedure involved the following steps:

- Perform variance analysis of the spin resolution magnetic field from each spacecraft to establish a new coordinate system, defined by the eigenvectors of the variance matrix. Use the rotation matrix from the best of these results, and rotate the high-resolution $(0.2 \mathrm{~s}) \mathrm{mag}-$ netic field from all spacecraft into the same local boundary normal coordinate system.

- Identify relative crossing time, crossing duration and $\mathbf{B}$ field jump for each spacecraft from profiles of the maximum variance components.

- Apply the multi-spacecraft method described below to determine magnetopause orientation, motion and thickness at each spacecraft.

- Use the observed magnetic field jump and the calculated thickness to estimate the current density at each spacecraft.

\subsection{Timing procedure}

In its simplest form, a multi-spacecraft determination of magnetopause orientation and motion makes use of the measured differences in crossing time and the known separation vectors between the spacecraft. The magnetopause thickness is thereafter calculated from the crossing duration and velocity. In order to determine the magnetopause crossing times and durations, we have used the maximum variance component, $B_{\max }$, of the magnetic field. This component is usually well defined and not very sensitive to either the time interval used for the variance analysis or the time resolution of the magnetic field data. Experience has shown that the spin resolution averages (with $\sim 4$-s spacing) are sufficient to establish the variance coordinate system (e.g., Sonnerup and Scheible, 1998). For the timing, we then used the 0.2-s resolution data.

Our determination of the crossing times and durations is schematically illustrated in Fig. 2, which shows a $B_{\max }$ transition, idealized as a Harris sheet-like profile, 
$B(t) \propto \tanh (t / \tau)$ (Harris, 1962). This profile, which often provides a reasonable fit to the actual measurements (e.g., Haaland et al., 2004), has the property that $76 \%$ of the total change in $B_{\max }$ occurs within a time interval $2 \tau$. The magnetopause thicknesses given in this study are defined in this fashion. To apply this concept to the real data, we first identified the base lines on either side of the magnetopause by visual inspection of the $B_{\max }$ profiles. For the crossing time, denoted by $t_{0}$ in Fig. 2, we usually took the time when $B_{\max }$ crosses the $50 \%$ level. Due to fluctuations in $B_{\max }$, this was not always possible. But as the method relies on relative timing only, any distinct boundary feature observed by all four spacecraft can be used for timing purposes. For the crossing duration we took the time between $12 \%$ and $88 \%$ of the complete $B_{\max }$ transition, corresponding to $76 \%$ of the transition shown in Fig. 2. Cases with ambigous timing were excluded from our analysis. This left us with 24 cases.

3.2 Determination of magnetopause orientation, motion, thickness, and current

For the determination of the orientation, motion and thickness of the magnetopause, several methods exist, all assuming a planar magnetopause. The simplest method assumes that the magnetopause moves across all four Cluster satellites with a constant velocity (Russell et al., 1983; Schwartz, 1998). This method, also referred to as the Constant Velocity Approach (CVA), uses crossing times and separation distances as inputs. Any difference in crossing duration from one spacecraft to the next is then attributed to thickness changes. For the spacecraft separation distances in the present study, the CVA method frequently predicts large thickness variations. A second method, the Constant Thickness Approach (CTA), was introduced by Haaland et al. (2004). As the name suggest, CTA assumes a constant thickness of the magnetopause. The crossing durations are additional inputs, and this method allows for magnetopause acceleration. CVA and CTA only give the same result when the crossing durations are the same for all four spacecraft.

Whether CTA or CVA is the better choice varies from case to case, but for a statistical study, it makes sense to use one and the same approach for all events. Noting that a constant thickness will generally not be strictly true either, we have derived a new method, which is a combination of CVA and CTA. This method has a boundary normal which is simply the average of the CTA and CVA normals, and a velocity calculated so that the magnetopause thickness variation is minimized; thus its name MTV (for Minimized Thickness Variation). The output from the MTV method is a single orientation of the magnetopause, but with different thicknesses and velocities for each individual spacecraft. Typically, both the velocity and thickness from the MTV method will lie in between the CVA and CTA results. Details of the MTV methods are given in the Appendix.

Our calculation of magnetopause current density is based on a simple one-dimensional model. The average current density is then given by

$J=\frac{0.76 \Delta B_{\max }}{\mu_{0} d}$,

where $d$ is the magnetopause thickness, and $0.76 \Delta B_{\max }$ is the jump of the maximum-variance magnetic field component across the magnetopause thickness, as defined above.

The curlometer technique (e.g., Robert et al., 1998), which utilizes Ampères law and magnetic field measurements from all four spacecraft, is based on an assumption of linear variations to determine the gradients in the magnetic field. Because the spacecraft separation is larger than the magnetopause thickness in most of our cases, this assumption is generally not satisfied, and the curlometer method will therfore underestimate the current densities.

\section{Single-spacecraft analysis}

While we used the four-spacecraft analysis for the determination of magnetopause speed, orientation and thickness, some properties of the magnetopause must be based on the analysis of individual spacecraft crossings. This applies to the classification of the crossings into tangential (TD) or rotational discontinuities (RD), and to the boundary layer identification.

\subsection{Walén test}

In order to determine whether the magnetopause crossings could be classified as TDs or RDs, we performed tests of the Walén-relation. The Walén relation, which is in effect a test of the tangential stress balance at the magnetopause, consists in first finding a deHoffmann-Teller (HT) frame, and then plotting the measured bulk velocity components, after transformation into the HT frame, against the corresponding components of the measured Alfvén velocities (Sonnerup et al., 1990; Khrabrov and Sonnerup, 1998b). The time intervals for the test were chosen to include as much of the magnetic field transition from the magnetosheath to the magnetosphere as was possible without reaching the point where plasma densities are too low to make the velocity measurements meaningful. Some cases had to be excluded from the test because the plasma density dropped so sharply within the magnetopause layer that meaningful flow velocities were only obtained for the outer part of the field transition.

The results are characterized in terms of the regressionline slope and correlation coefficients between $\left(\mathbf{V}-\mathbf{V}_{\mathbf{H T}}\right)$ and $\mathbf{V}_{\mathbf{A}}$. A positive (negative) slope of the regression means that $B_{n}$ and $V_{n}$ have the same (opposite) signs. Assuming that any flow across the magnetopause is always pointing inward $\left(V_{n}<0\right)$, the slope thus tells us the sign of $B_{n}$. For the configuration illustrated in Fig. 3, $B_{n}$ is negative (pointing inward), sunward of the X-line and positive (pointing outward), on the tailward side. A positive slope thus indicates a crossing sunward of the X-line, and a negative slope indicates a crossing on the tailward side. On the tailward branch of an X-line 


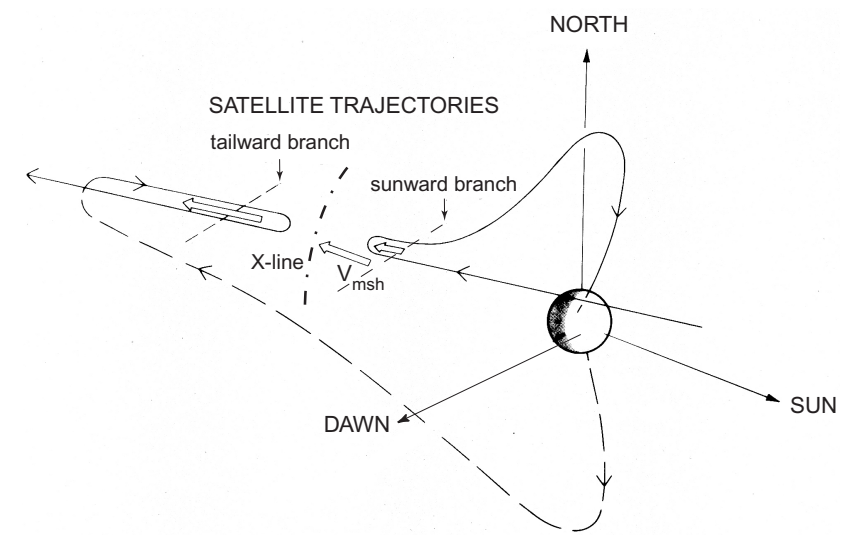

Fig. 3. A sketch that illustrates reconnection between a tailward stretched magnetospheric field line in the Northern Hemisphere past dawn with an oppositely directed magnetosheath field line. The light arrows indicate plasma flow. The orientation of the X-line is shown by the dot-dashed line. Spacecraft crossings of the tailward and sunward branches are schematically indicated. The geometry shows the case with $180^{\circ}$ shear. For magnetosheath fields not anti-parallel to the magnetosphere field, the X-line is tilted more obliquely. Figure adapted from Gosling et al. (1986).

configuration, the magnetic curvature forces have the same sense as the magnetosheath flow and thus lead to enhanced flow speeds (plasma jetting). For a crossing on the sunward side the curvature forces have the opposite sense and thus no jetting would occur.

For an ideal RD, the magnitude of the slope of the regression line should be equal to unity. But several effects can lead to lesser slopes. These include (1) stresses coming from the tangential component of $\nabla\left(p+B_{z}{ }^{2} / 2 \mu_{0}\right)$, where $B_{z}$ is the guide field during reconnection; (2) the anchoring of the guide field in slower-moving plasma on the two sides of a reconnection channel; (3) the presence of $\mathrm{O}^{+}$ions not resolved in the measurements, leading to incorrect Alfvén velocities. As we will see later, there is strong evidence that slopes as low as 0.5 can be indicative of an RD.

The Walén tests were performed only for $\mathrm{C} 1$ and $\mathrm{C} 3$ crossings, for which reliable ion flow and density data from the CIS/HIA instruments are available. For some selected cases, Walén test results are reported in Sect. 5, while the overall statistics are reported in Sect. 6.3. It has been argued (Scudder et al., 1999) that one should use electron bulk velocities for the Walén tests, because the magnetic field is tied to the electron fluid, and the ion bulk velocity will differ from the electron bulk velocity if electric currents are flowing. But as we will see later, this difference is small in the cases we have analyzed.

\subsection{Boundary layer}

Particle transfer across the magnetopause generates a boundary layer of magnetosheath-like plasma earthward of the magnetopause. If the magnetopause is locally a TD, then local plasma transfer can only be via some kind of diffu-

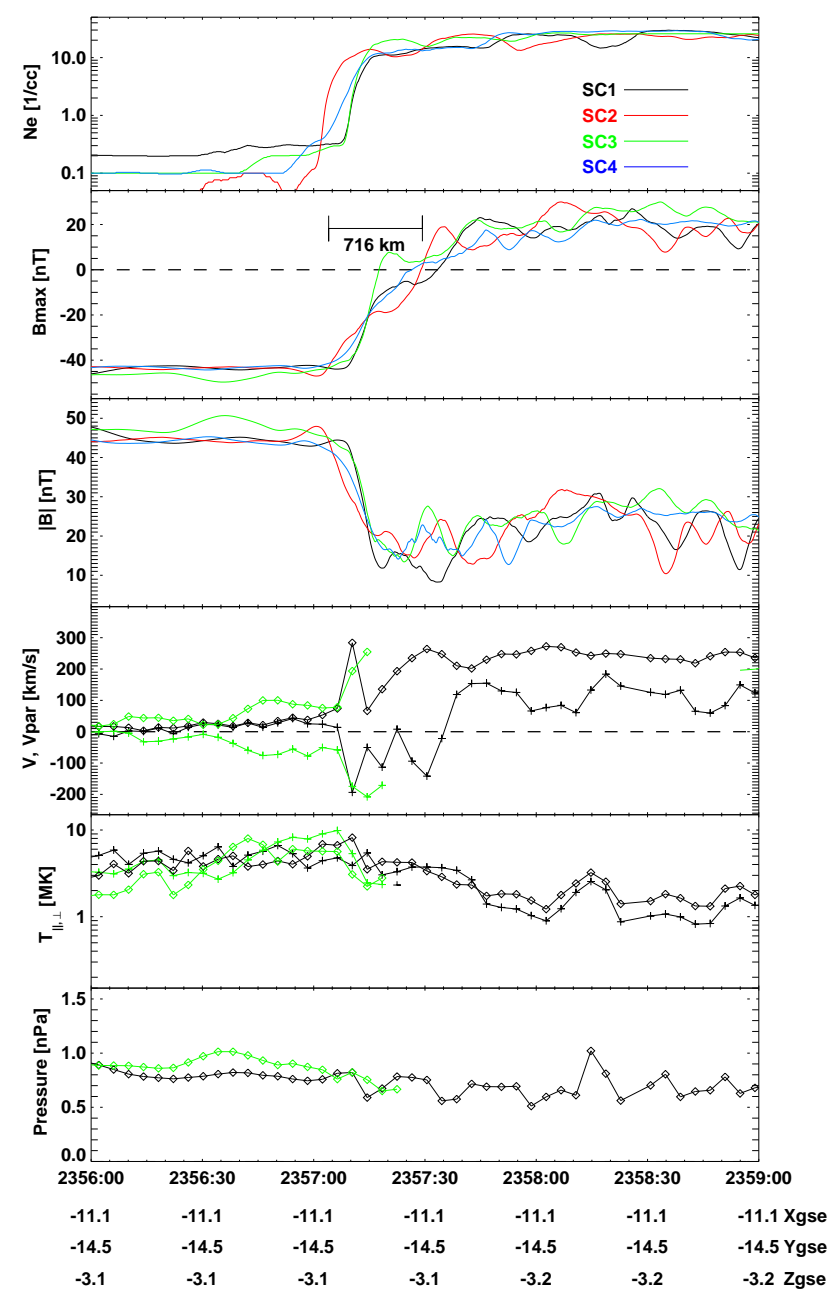

Fig. 4. Plasma and magnetic field data for the outbound crossing near 23:57 UT on 4 July 2001. From top to bottom, the panels are: plasma density (from EFW), maximum variance component and magnitude of the magnetic field (from FGM) for all four Cluster spacecraft, plotted as 6-s running averages with 0.2-s spacing; magnitude (diamonds) and parallel component (plus symbols) of the ion bulk velocities; parallel (plus symbols) and perpendicular (diamonds) ion temperatures; total pressure (plasma plus magnetic), all from CIS-HIA on spacecraft $\mathrm{C} 1$ and $\mathrm{C} 3$, plotted at spin resolution $(\sim 4 \mathrm{~s})$. There is a data gap in the $\mathrm{C} 3$ plasma data right after the magnetopause transition. The magnetopause thickness from $\mathrm{C}$, calculated as described in Sect. 3.2, was $716 \mathrm{~km}$ for this case, and is shown as a horizontal bar in the $B_{\max }$ panel. The time axis applies to the $\mathrm{C} 1$ measurements. The $\mathrm{C} 2, \mathrm{C} 3$, and $\mathrm{C} 4$ data have been shifted and stretched, in order to line up the crossings and turn them into spatial profiles, as described in the text. The position of $\mathrm{C} 1$ (in GSE coordinates) is given along the UT axis. Note the sharp rise in density at the inner edge of the magnetopause current layer.

sive process. As the plasma in the boundary layer tends to flow along the magnetopause at some fraction of the magnetosheath speed, the locally observed boundary layer will reflect the accumulated entry occurring upstream from the observation site. Diffusion therefore creates a boundary layer with a thickness that increases with increasing distance from 


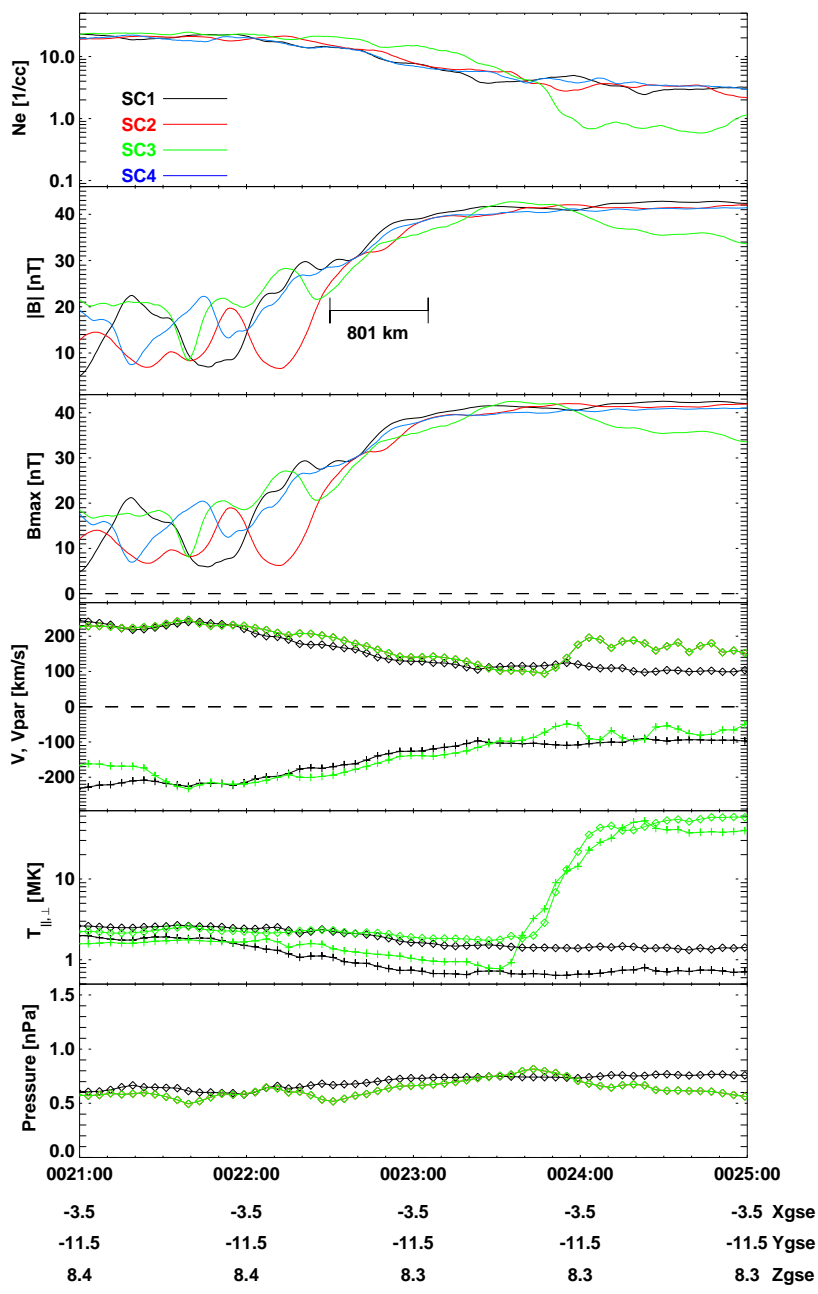

Fig. 5. Plasma and magnetic field data for the inbound crossing near 00:22 UT on 5 July 2001, in the same format as Fig. 4. Note that C3 enters the hot plasma of the plasma sheet near 00:24 UT.

the subsolar point. If, on the other hand, the magnetopause is an RD, plasma enters the magnetosphere via fluid flow, at a speed, $V_{n}$, given by the Alfvén velocity based on the normal magnetic field component, $B_{n}$. This inflow generates a wedge-shaped boundary layer emanating from the reconnection site (Levy et al., 1964). In this situation, the boundary layer thickness will increase with increasing distance from the reconnection site (the X-line). The identification of a boundary layer requires comparisons between the magnetic field and plasma density profiles measured across the magnetopause.

\section{Examples}

In this section we discuss six magnetopause crossings in order to illustrate the range of characteristics of the magnetopause and boundary layer on this pass. For this discussion, the relative timing of the spacecraft crossings is unimportant, and in Figs. 4-9 the traces from C2, C3 and C4 have therefore been shifted and stretched (or compressed) relative to that of $\mathrm{C} 1$, so that the crossing times line up, and the four profiles represent spatial profiles, at least near the magnetopause, even though they are plotted against the $\mathrm{C} 1$ time.

The necessary time shift is simply a displacement of the $\mathrm{C} 2, \mathrm{C} 3$ and $\mathrm{C} 4$ curves based on the difference between their crossing times and that of $\mathrm{C} 1$. The time stretching of the $\mathrm{C} 2, \mathrm{C} 3$ and $\mathrm{C} 4$ curves is done in inverse proportion of their magnetopause speeds relative to that of $\mathrm{C} 1$. Thus, the plotted interval for each spacecraft is given by:

$T_{S C n}=T_{S C 1} * \frac{V_{M T V S C 1}}{V_{M T V S C n}}, \quad n=2,3,4$,

where $V_{M T V S C n}$ is the magnetopause velocity according to the MTV method (see Sect. 3.2) for spacecraft $n$, and $T_{S C n}$ is the corresponding time interval shown.

\section{$5.1 \quad 23: 57$ UT crossing (\#1)}

This crossing is the first on this orbit and is labelled 1 in Fig. 1. The plasma and magnetic field data are shown in Fig. 4. Minimum variance analysis (MVAB) was performed on the $\mathrm{C} 1$ magnetic data and the resulting rotation matrix was then used to transform the magnetic field from all spacecraft into the same coordinate system. The magnetopause crossing is recognized as the transitions in the magnetic field magnitude (from $\sim 45 \mathrm{nT}$ to $\sim 20 \mathrm{nT}$ ) and in the maximum variance component (from $\sim-45 \mathrm{nT}$ to $\sim 20 \mathrm{nT}$ ). The total change in $B_{\max }$ corresponds to a rotation of almost $180^{\circ}$ across the magnetopause.

At the time the magnetic field begins its transition, i.e. at the inner edge of the magnetopause current layer, the plasma density increases abruptly from a magnetospheric level of a few tenths of $\mathrm{cm}^{-3}$ to $10 \mathrm{~cm}^{-3}$. There is another increase by a factor of two near the outer edge of the magnetopause. Over the width of the magnetopause the plasma velocity increases to $250 \mathrm{~km} \mathrm{~s}^{-1}$. The ion temperature, which is not meaningful until shortly before the magnetopause crossing, when the density becomes measurable by HIA, shows a slight drop as expected for the exit from the magnetosphere. The total pressure (magnetic pressure plus ion thermal pressure) is reasonably constant, as expected across the magnetopause. The fact that the plasma density shows no significant enhancement before the magnetopause encounter means that on this crossing there was no magnetopause boundary layer, i.e. no layer of magnetosheath-like plasma located inward of the magnetopause. Using the MTV-method described in Sect. 3.2 on this set of crossings, we obtain magnetopause thicknesses of $716,715,706$, and $680 \mathrm{~km}$ for $\mathrm{C} 1$ to $\mathrm{C} 4$, respectively. For reference, we have plotted the thickness for the $\mathrm{C} 1$ crossing as a horizontal bar in Fig. 4.

To determine whether the magnetopause was a TD or an $\mathrm{RD}$, we performed a test of the Walén relation. As described in Sect. 4.1, this test compares the plasma flow velocity in the deHoffmann-Teller frame with the Alfvén velocity. From the low values for the correlation coefficient and/or slope of the 


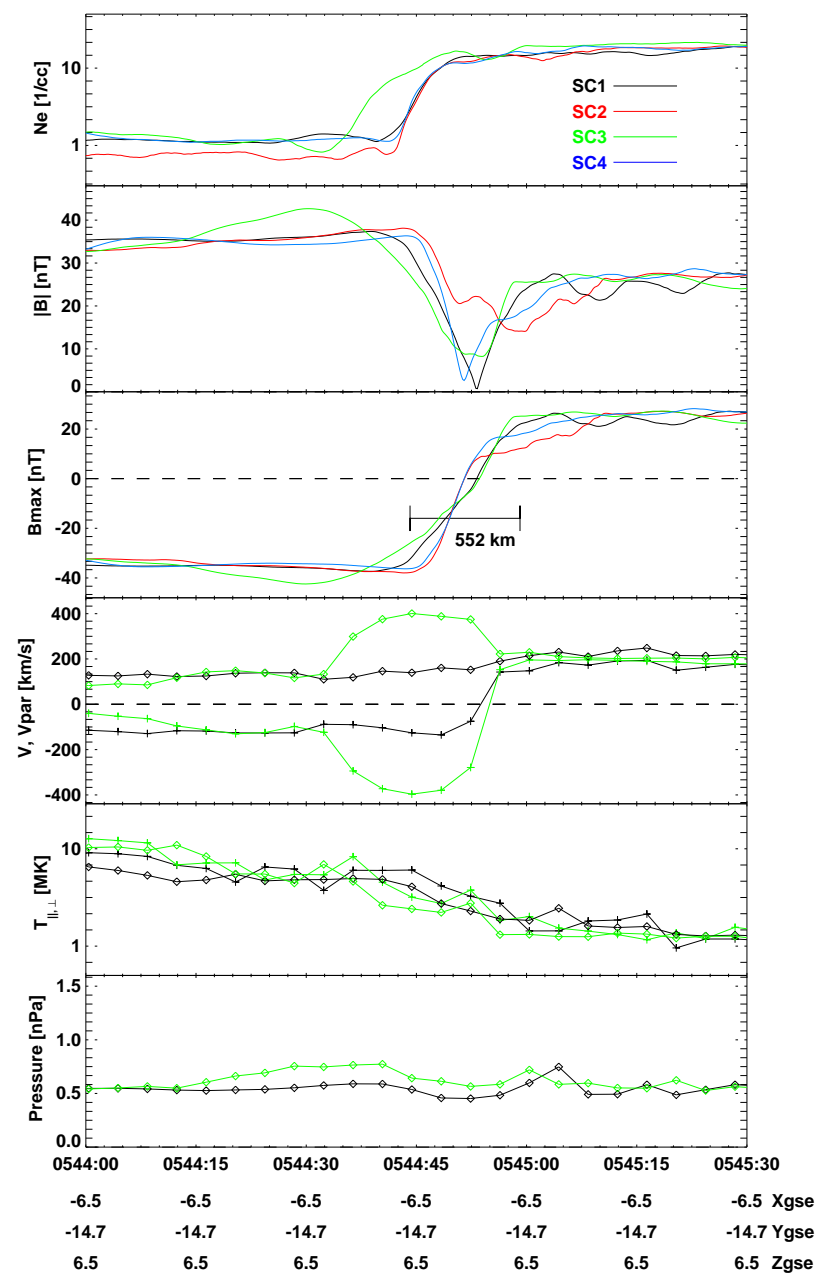

Fig. 6. Plasma and magnetic field data for the outbound crossing near 05:45 UT on 5 July 2001. Plot format and labelling as in Fig. 4. Note the pronounced plasma jetting observed by $\mathrm{C} 3$, directed in the - B direction $\left(V_{\|}<0\right)$ which is not observed by $\mathrm{C} 1$ (4th panel).

regression line found for this case, it is concluded that the magnetopause was a TD on this occasion. By definition, a TD does not permit local plasma entry by fluid flow. The fact that the observed plasma density stays at the low magnetospheric values until the spacecraft enters the magnetopause current layer is consistent with such an impermeable boundary.

\section{$5.2 \quad 00: 22$ UT crossing (\#2)}

This inbound crossing, shown in Fig. 5, differs from the previous example in that the magnetic field shear is small, only $30^{\circ}$. The change in $B_{\max }$ is correspondingly much smaller. The positive sign of the shear indicates a northerly directed magnetosheath field. The magnetopause thickness obtained for the $\mathrm{C} 1$ crossing is $\sim 800 \mathrm{~km}$. The present crossing is also distinguished by the presence of a boundary layer of magnetosheath plasma inside the magnetopause, as evidenced by

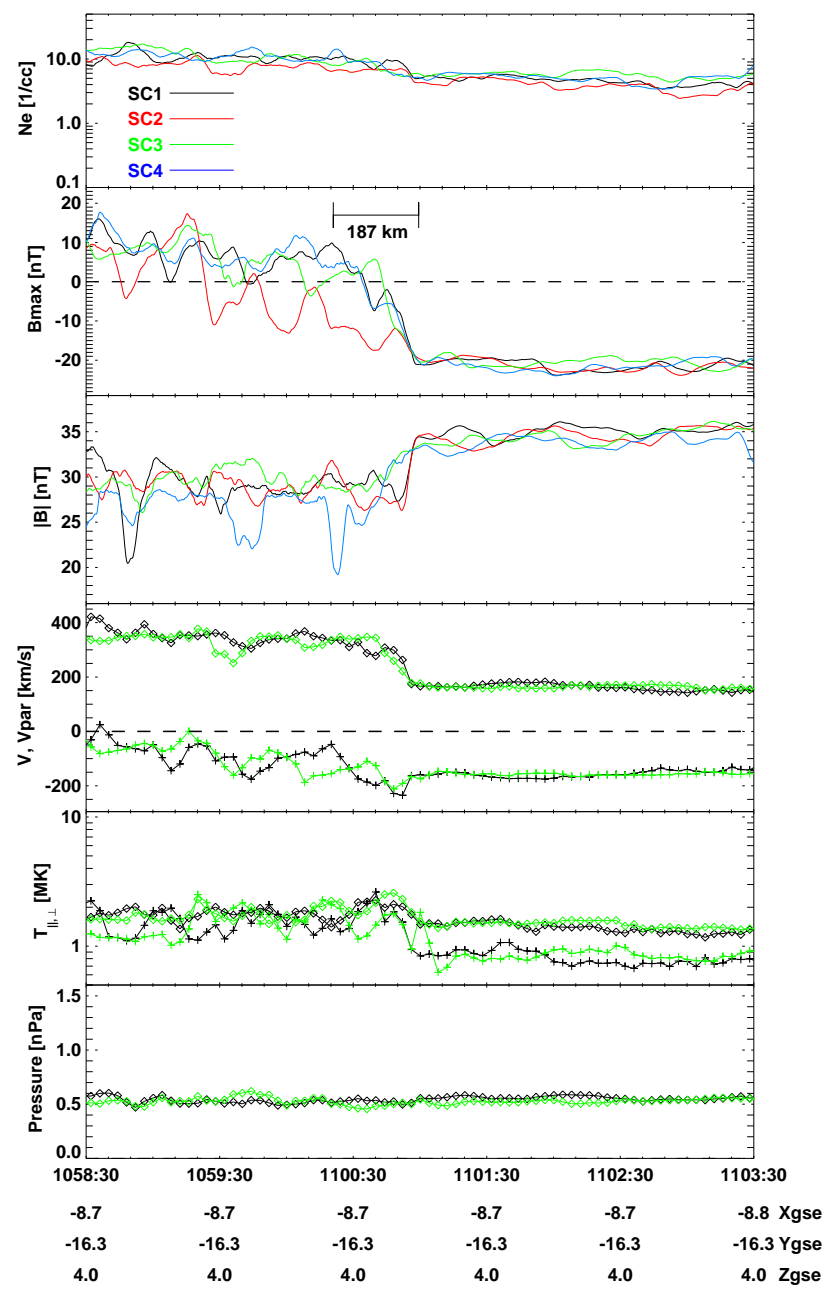

Fig. 7. Plasma and magnetic field data for the inbound magnetopause crossing at 11:01 UT on 5 July 2001. Plot format and labelling as in Fig. 4. Note the gradual density drop, the field-aligned plasma flow, and the large temperature anisotropy on the magnetopsheric side, which are the characteristics of the plasma mantle.

the lack of a sharp density drop at the inner edge of the magnetopause. A closer look shows that the spacecraft have actually entered the high latitude boundary layer known as the plasma mantle (Rosenbauer et al., 1975). Evidence for the plasma mantle are the alignment of the flow velocity with the magnetic field (as indicated by the near-equality of $V$ and $V_{\|}$), and the large temperature anisotropy, $T_{\perp} / T_{\|}$.

This case also differs in another interesting aspect. While in the previous example the time-series measured by the four spacecraft were quite similar, the profiles of density, velocity and temperature recorded by $\mathrm{C} 3$ are now quite different from those of the other spacecraft. In one minute $\mathrm{C} 3$ has gone from the magnetosheath across the magnetopause into the hot plasma sheet (with $T=\sim 6 \cdot 10^{7} \mathrm{~K}$ ), while the other three spacecraft are still in the magnetosheath. There is an indication of a boundary layer in the $\mathrm{C} 3$ data, but its thickness must have been less than the spacecraft separation, otherwise the 
other three spacecraft could not have remained in the magnetosheath. (This time sequence is not apparent in Fig. 5 because in constructing the figure, the data were shifted so that the magnetopause crossings all line up.) When $\mathrm{C} 1, \mathrm{C} 2$, and C4 finally cross the magnetopause ( $~ 90$ s after C 3 ), they enter the boundary layer, in the form of the cold plasma mantle (with $T=\sim 1 \cdot 10^{6} \mathrm{~K}$ ) and remain there, at nearly the same density levels, for several minutes. This is an indication that when those spacecraft entered the boundary layer, it must have been much thicker than the spacecraft separation. The explanation for this difference could either be temporal, implying a very rapid change in boundary layer thickness, or spatial, implying the existence of a boundary between different plasma regimes: where $\mathrm{C} 3$ crossed, the plasma sheet abutted the magnetopause (almost) directly, while there was a thick plasma mantle where the other three spacecraft crossed.

\section{$5.3 \quad 05: 45$ UT crossing (\#13)}

This outbound crossing (with almost $180^{\circ}$ shear) has been chosen to illustrate that the character of the magnetopause can change rapidly. Figure 6 shows that C3 observes plasma jetting when it enters the magnetopause, while $\mathrm{C} 1$, which crossed $25 \mathrm{~s}$ earlier, does not. (This relative timing is not apparent from the figure because it shows the inferred spatial profiles rather than the original time series, as described at the beginning of Sect. 5.)

The Walén test for $\mathrm{C} 3$ yields a slope of -0.76 (with correlation coefficient of -0.96). As described in Sect. 4.1, the negative slope means that the $\mathrm{C} 3$ crossing occurred tailward of an X-line, where the magnetic curvature forces lead to plasma jetting, as observed. The situation exists as shown by the tailward branch crossing in Fig. 3. The slope determined for $\mathrm{C} 1$ is only 0.19 . Thus, the $\mathrm{C} 1$ crossing either occurred very near the $\mathrm{X}$-line (where the Walén relation does not apply), or at the time of the $\mathrm{C} 1$ crossing the magnetopause was a TD and changed to an RD over a short period of time. We believe that the latter case applies, because the $\mathrm{C} 1$-to-C3 separation vector was nearly aligned with the magnetopause normal at this time, and the $\mathrm{C} 1$ and $\mathrm{C} 3$ crossings must therefore have been close in space. Thus, it seems that between the times of the $\mathrm{C} 1$ and $\mathrm{C} 3$ crossings an $\mathrm{X}$-line must have formed further upstream.

Comparing the density profiles (top panel of Fig. 6) with those of $B_{\max }$ (second panel), it is evident that during the $\mathrm{C} 1, \mathrm{C} 2$, and $\mathrm{C} 4$ crossings there was no boundary layer, while $\mathrm{C} 3$ observed a thin boundary layer. This is consistent with the conclusion that the magnetopause was a TD during the $\mathrm{C} 1, \mathrm{C} 2$, and $\mathrm{C} 4$ crossings, but had become an RD when C3 crossed it. Comparing the width of that boundary layer with the magnetopause width of $\sim 550 \mathrm{~km}$ (shown by the horizontal bar in the figure), the boundary layer thickness observed by $\mathrm{C} 3$ may be estimated at around $250 \mathrm{~km}$. The fact that the boundary layer is so thin probably means that the $\mathrm{C} 3$ crossing occurred close to the X-line, where the wedge-shaped boundary layer is expected to be very narrow. If the X-line was indeed close to the $\mathrm{C} 3$ crossing, then it becomes significant that the magnetosheath flow speed (at $205 \mathrm{~km} \mathrm{~s}^{-1}$ ) is substantially larger than the local Alfvén speed $(140 \mathrm{~km}$ $\mathrm{s}^{-1}$ ), which is not usually considered a likely condition for the formation of an X-line, unless the X-line is moving. We will return to this point in Sect. 6 .

\subsection{1:01 UT crossing (\#20)}

This inbound crossing with $65^{\circ}$ magnetic shear (i.e. a northerly directed magnetosheath field), shown in Fig. 7, is characterized by three properties. First, the magnetopause is an RD. This conclusion is based on the slopes of the Walén relation, 0.60 and 0.72 for $\mathrm{C} 1$ and $\mathrm{C} 3$, respectively. Second, the positive sign of the Walén slopes implies that the crossing occurred sunward and southward of an X-line. Third, following the magnetopause crossing the spacecraft are immersed in the most extended boundary layer of the entire day. Noting the smooth density profiles (top panel), the alignment of the plasma flow velocity with the magnetic field (indiated by the near-equality of $V$ and $V_{\|}$, fourth panel), and the large ion temperature anisotropy (fifth panel), one concludes that Cluster has actually encountered the plasma mantle. The magnetopause is rather thin at this time, around $190 \mathrm{~km}$ for the $\mathrm{C} 1$ crossing.

\subsection{1:49 UT crossing (\#21)}

This high-shear $\left(155^{\circ}\right)$ outbound pass, shown in Fig. 8, has been chosen for two reasons. First, it has a density drop near the center of the magnetopause current layer, followed by a density plateau until its inner edge. Such plateaus have been noted earlier in single-spacecraft data (Song et al., 1993). As this plateau is seen sequentially by all four spacecraft, it is a true spatial feature, and not the result of dwelling at a fixed location relative to the magnetopause, as could not have been excluded in single-spacecraft observations. The magnetopause thickness is $1960 \mathrm{~km}$, and there is no boundary layer. Second, C1 and C3 show pronounced plasma jetting, indicating that the magnetopause is an $\mathrm{RD}$ and that the crossing occurred through the tailward branch. Thus, the geometry for this case is as shown in Fig. 3 for crossings of the tailward branch, except that the magnetosheath field is not exactly opposite to the magnetosphere field in the present case. We obtain Walén slopes of -0.67 and -0.60 , with correlation coefficients of -0.98 and -0.89 , for $\mathrm{C} 1$ and $\mathrm{C} 3$, respectively. It should be noted, however, that the inner part of the magnetopause current layer had to be excluded from the test to obtain these high values. This implies that the plasma observed further inward has not entered locally.

\subsection{5:26 UT crossing (\#29)}

This outbound crossing with $-140^{\circ}$ shear (i.e. a tailward directed field with a southerly component) shown in Fig. 9, is considered an RD crossing through the tailward branch, 


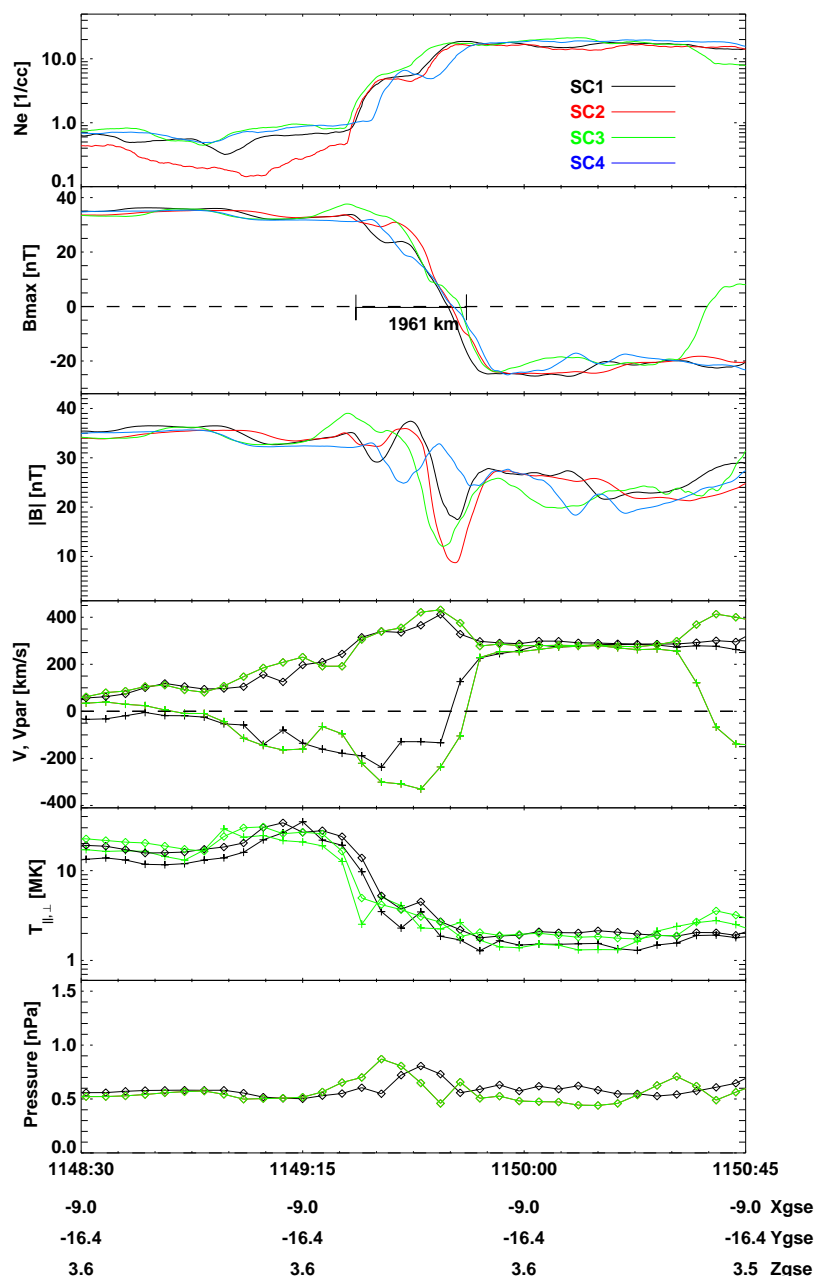

Fig. 8. Plasma and magnetic field data for the crossing near 11:49 UT on 5 July 2001. Plot format and labelling as in Fig. 4. Note the density plateau within the magnetopause, and the enhanced plasma flow speed observed by both $\mathrm{C} 1$ and $\mathrm{C} 3$.

as evident from the plasma jetting seen on $\mathrm{C} 1$ and $\mathrm{C} 3$. The Walén tests, however, yield slopes of only -0.60 and -0.46 for $\mathrm{C} 3$ and $\mathrm{C} 1$, respectively. As already mentioned in Sect. 4.1, there are a number or reasons why RDs can have slopes less than one and this event supports this conclusion (see Sect. 6.3).

The magnetopause thickness obtained for the $\mathrm{C} 1$ crossing is $\sim 890 \mathrm{~km}$. The plasma density stays at the magnetosheath level until the inner edge of the magnetopause, followed by an extended boundary layer with a density plateau at $2 \mathrm{~cm}^{-3}$, before dropping below $1 \mathrm{~cm}^{-3}$.

\section{Statistical results}

\subsection{Magnetopause thickness, speed, and current}

Applying the technique described in Sect. 3 to the 24 crossings by all four spacecraft, we obtain magnetopause thicknesses, speeds and current densities for a total of 96 cross-

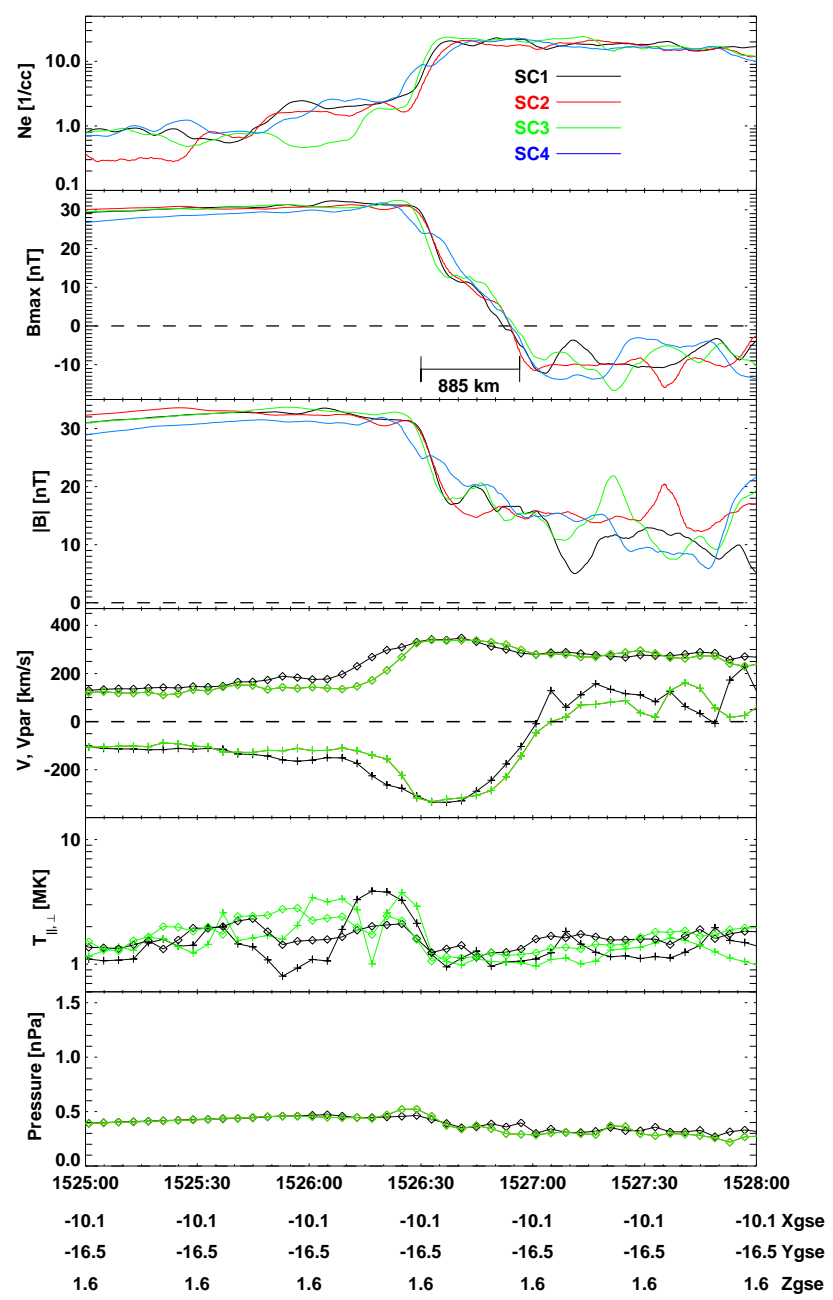

Fig. 9. Plasma and magnetic field data for the crossing at 15:26 UT on 5 July 2001. Plot format and labelling as in Fig. 4. Note the density plateau on the magnetospheric side of the magnetopause.

ings. Figure 10 shows histograms of these quantities. Table 6.1 lists the individual thicknesses. They range from 100 to $2500 \mathrm{~km}$, with a peak occurrence in the $400-800 \mathrm{~km}$ bin, and an average of $753 \mathrm{~km}$. The speeds range from less than $10 \mathrm{~km} \mathrm{~s}^{-1}$ up to $180 \mathrm{~km} \mathrm{~s}^{-1}$, with a peak in the $20-40 \mathrm{~km} \mathrm{~s}^{-1}$ bin, and an average of $48 \mathrm{~km} \mathrm{~s}^{-1}$. These results are quite similar to the earlier statistics from ISEE-1 and -2 dual spacecraft measurements (Berchem and Russell, 1982), although those were obtained for the dayside magnetopause, covering local times between 08 and $17 \mathrm{~h}$. Their average thickness was somewhat higher $(923 \mathrm{~km})$, but one should note that Berchem and Russell (1982) used the full 0-100\% transition in $B_{\max }$ to define the thickness, which would make their values a bit higher. Similar average thicknesses $(900 \mathrm{~km})$ were also reported from AMPTE/IRM single-spacecraft analysis of dayside magnetopause crossings between 08 and 16h local time (Phan and Paschmann, 1996).

Ion gyroradii and ion inertial lengths in the adjoining magnetosheath were typically $40-80 \mathrm{~km}$ for these crossings. 

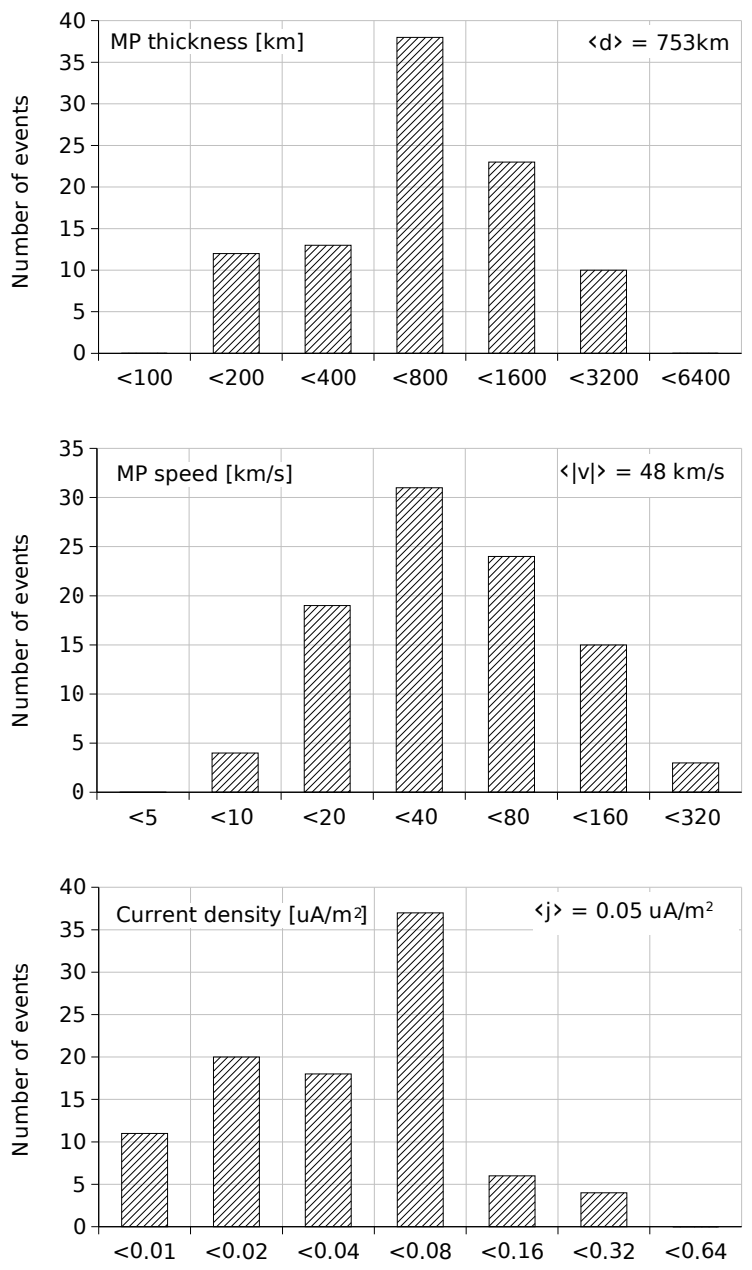

Fig. 10. Histograms of magnetopause (MP) speed, thickness and current density for 24 dawn flank magnetopause crossings by all 4 spacecraft on 4/5 July 2001, resulting in a total of 96 individual crossings. Note that the bins are logarithmically spaced.

Scaling the magnetopause thicknesses by those characteristic lengths therefore does not alter the large thickness range we have observed. The plasma $\beta$ in the adjoining magnetosheath was in the range 0.5 to 2 . Thus, our data do not allow one to check the significant reduction in average thickness reported for $\beta>10$ crossings by ISEE (Le and Russell, 1994) and AMPTE/IRM (Phan and Paschmann, 1996).

As shown in Fig. 10, current densities range from $<0.01 \mathrm{uA}$ up to $\sim 0.3 \mathrm{uA}$, with an average value of $0.05 \mathrm{uA}$. The factor 30 between the highest and lowest value is the same as for the thickness range, and the current density roughly scales inversely with the thickness, thus preserving a nearly constant net current. As explained in Sect. 3.2, the curlometer technique will underestimate the current densities for the events in this study. Taking $15 \mathrm{~cm}^{-3}$ for the typical magnetosheath plasma density on this pass, the average current density implies an average drift velocity between ions and electrons of $\sim 30 \mathrm{~km} \mathrm{~s}^{-1}$. This point will become important later.
Table 1. Magnetopause thicknesses for 96 crossings.

\begin{tabular}{rrrrr}
\hline Time & $d_{C 1}[\mathrm{~km}]$ & $d_{C 2}[\mathrm{~km}]$ & $d_{C 3}[\mathrm{~km}]$ & $d_{C 4}[\mathrm{~km}]$ \\
\hline $23: 57$ & 716 & 715 & 706 & 680 \\
$00: 22$ & 802 & 728 & 766 & 778 \\
$00: 30$ & 234 & 235 & 234 & 234 \\
$00: 44$ & 657 & 749 & 688 & 652 \\
$02: 06$ & 177 & 177 & 177 & 177 \\
$02: 11$ & 316 & 268 & 314 & 278 \\
$02: 40$ & 855 & 1070 & 961 & 921 \\
$05: 34$ & 119 & 122 & 122 & 122 \\
$05: 45$ & 552 & 740 & 642 & 525 \\
$06: 23$ & 372 & 581 & 490 & 410 \\
$08: 17$ & 511 & 548 & 634 & 662 \\
$11: 01$ & 188 & 188 & 188 & 188 \\
$11: 49$ & 1961 & 1895 & 1674 & 1822 \\
$12: 01$ & 1483 & 1478 & 1350 & 1397 \\
$12: 14$ & 313 & 284 & 239 & 202 \\
$12: 44$ & 439 & 464 & 439 & 444 \\
$12: 49$ & 349 & 366 & 436 & 376 \\
$13: 41$ & 884 & 1052 & 1078 & 1045 \\
$14: 06$ & 443 & 459 & 459 & 455 \\
$15: 11$ & 538 & 575 & 514 & 561 \\
$15: 26$ & 886 & 911 & 1138 & 946 \\
$15: 49$ & 2148 & 2318 & 2265 & 2389 \\
$17: 02$ & 1049 & 908 & 1048 & 928 \\
$17: 28$ & 1537 & 1721 & 1264 & 1662 \\
\hline & & & &
\end{tabular}

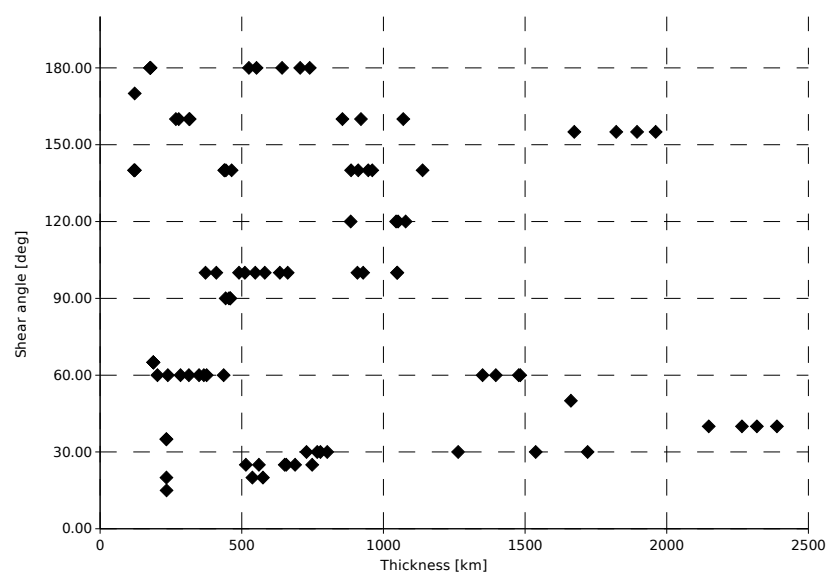

Fig. 11. Magnetic shear plotted versus magnetopause thickness for the 96 crossings.

Early ISEE results by (Elphic and Russell, 1979) indicated a correlation between magnetopause current layer thickness and magnetic shear, although a later study (Berchem and Russell, 1982) did not confirm this result. Our results, shown in Fig. 11, do not suggest any clear shear dependence either.

\subsection{Surface waves}

To investigate if surface waves are responsible for at least some of the magnetopause crossings on this day, we have looked for systematic variations in magnetopause 

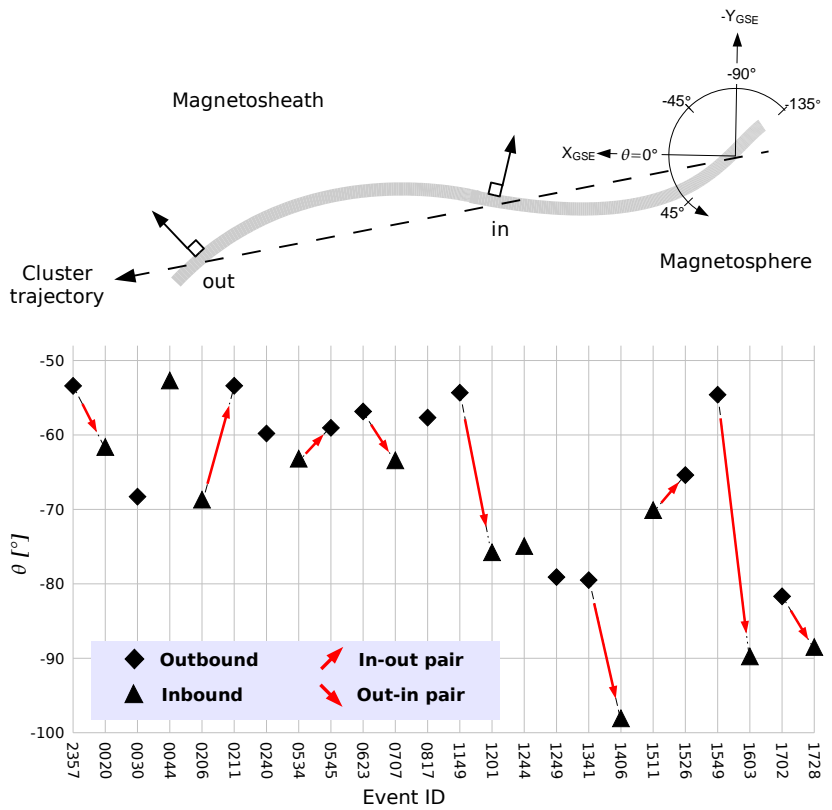

Fig. 12. Top: Illustration of surface waves on the dawn flank magnetopause and definition of azimuth angle. The boundary normals of the inbound and outbound crossings should have different azimuthal angles. Bottom: azimuth angle, $\theta$, of the boundary normal for the 24 crossings, ordered chronologically from left to right along the abcissa. For most of the cases, there is a systematic difference in the normal direction for inbound (triangles) and outbound (diamonds) crossings. The red arrows indicate crossing pairs with an orientation change as expected from surface waves.

orientation. From the four-spacecraft analysis we obtained the magnetopause orientation for the 24 crossings that involved all four spacecraft. Figure 12 shows the azimuthal angle, $\theta$, of the magnetopause normals for these 24 cases. This angle is defined as $\theta=\tan ^{-1}\left(n_{x} / n_{y}\right)$. An azimuth angle of $0^{\circ}$ thus means a normal pointing in the GSE $+X$ direction, $-90^{\circ}$ a normal vector pointing in the GSE -Y direction. The figure shows that in cases where two subsequent crossings represent an in/out (or a out/in) pair, the inbound crossing has a larger azimuth angle than the outbound crossing, consistent with the passage of a surface wave, as illustrated in the top of Fig. 12.

Since the observed wave motion is not strictly periodic, it is difficult to draw any conclusions about the wavelengths. The time interval of the in-out pairs in Fig. 12 varies from $5 \mathrm{~min}$ up to $26 \mathrm{~min}$, but these times may contain several wave periods. For reference, a 5 min period corresponds to a wave length of around $7 \mathrm{R}_{\mathrm{E}}$, assuming that the waves propagate at half the observed magnetosheath flow speed.

For magnetopause traversals induced by surface waves, one can distinguish crossings of the leading and trailing edges of the waves. To investigate whether there are systematic differences in thicknesses and/or speed between the leading and trailing edges, we have separated the crossings into leading edge (i.e. inbound) crossings, and trailing edge (i.e. outbound) crossings. We found that the inbound crossings
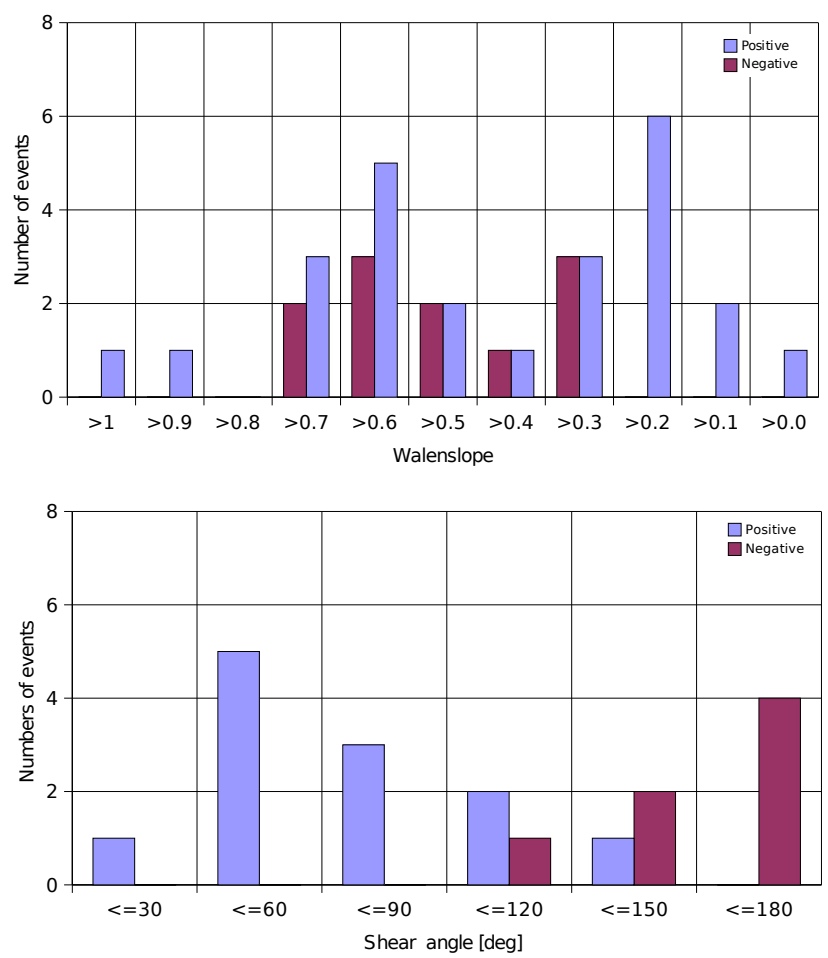

Fig. 13. Top: Histogram of Walén slopes, for all cases where the correlation coefficient magnitude exceeded 0.85. Positive and negative slopes are shown with different colors. Bottom: Subset of cases with slopes of magnitude $>0.5$, divided according to the sign of the slopes, versus the magntitude of the magnetic shear across the magnetopause.

have an average thickness of $613 \mathrm{~km}$, while the outbound crossings have an average thickness of $861 \mathrm{~km}$. This difference is, however, not statistically significant. There is also no significant speed difference.

\subsection{RD vs. TD statistics}

In Sect. 5 we already reported the results of the Walén test, described in Sect. 4.1, for a number of crossings. In this section we will present the overall statistics. In addition to the 24 crossings by all four spacecraft, there were several welldefined crossings in which fewer than four were involved. With those additions, we had a total of 60 crossings available for the statistical analysis, 31 from $\mathrm{C} 1$ and 29 from C3.

Of these 60 cases, 36 gave correlation coefficients $|c c|>0.85$ between $\left(\mathbf{V}-\mathbf{V}_{\mathbf{H T}}\right)$ and $\mathbf{V}_{\mathbf{A}}, 16$ for $\mathrm{C} 1$ and 20 for C3. Figure 13 (top) shows a histogram of the slopes of these 36 cases. The magnitude and sign of the Walén slope vary rapidly from crossing to crossing, but the $\mathrm{C} 1$ and $\mathrm{C} 3$ results (not separated in the figure) are closely matched in magnitude and sign. In fact, of the 13 crossings where we have obtained results (with $|c c|>0.85$ ) for both spacecraft, 11 had very similar slopes. This result lends credence to the reliability of the method. We note here that the use of ion bulk velocities for the Walén test does not introduce significant errors, 
a)

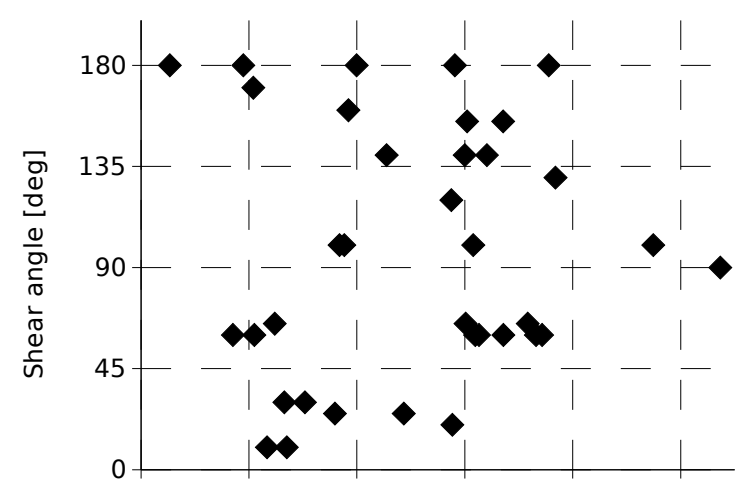

b)

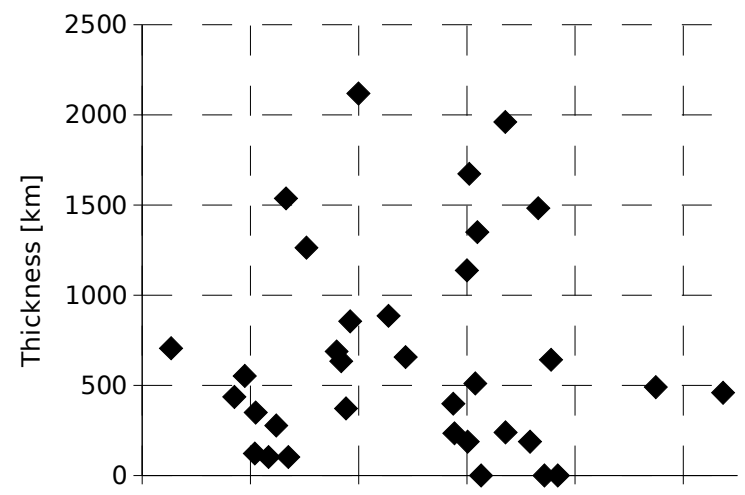

c)

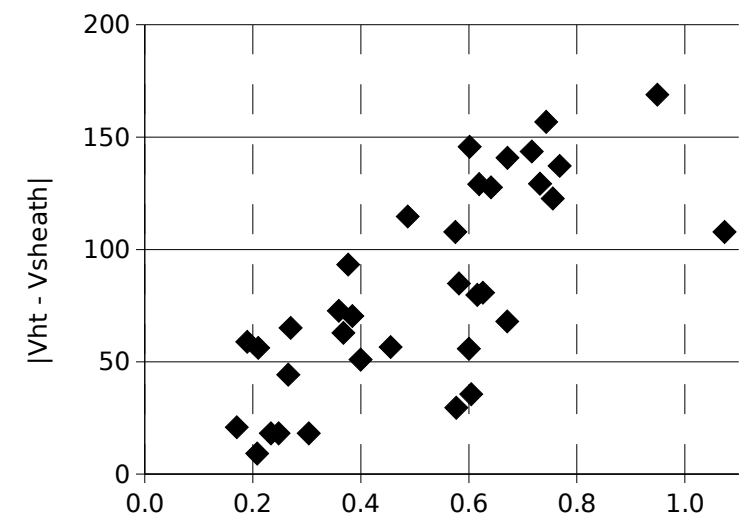

Fig. 14. Magnitude of the magnetic shear (a), magnetopause thickness (b), and magnitude of the velocity residue $\left(\mathbf{V}_{m s h}-\mathbf{V}_{H T}\right)(\mathbf{c})$, plotted versus the magnitude of the Walén relation slope, for all cases where the correlation coefficient magnitude exceeds 0.85 . While there is no correlation of the Walén slope with either magnetic shear or magnetopause thickness, there is a clear correlation with the difference between magnetosheath and deHoffmann-Teller velocities, indicating that magnetic coupling increases with increasing Walén slope.

and thus cannot explain the deviations from unity because, as shown in Sect. 6.1, typical ion-electron velocity differences were only $30 \mathrm{~km} \mathrm{~s}^{-1}$.

As already discussed in Sect. 4.1, RDs should ideally result in slopes with magnitude 1 , but other effects could cause deviations from 1. Perfect agreement between the observed plasma flows and those predicted for an RD is rare. In most cases reported in the literature the observed flows are smaller than predicted (e.g., Sonnerup et al., 1981; Gosling et al., 1986; Paschmann et al., 1986; Phan et al., 1996). The wellpronounced plasma jets in Fig. 8 had slopes of -0.67 (C1) and -0.60 (C3). Similarly, the jets in Fig. 9 have slopes of $-0.46(\mathrm{C} 1)$ and $-0.60(\mathrm{C} 3)$. As no alternate explanation for such plasma jetting appears to exist, we feel justified to classify cases with slopes in excess of 0.5 as RDs.

Using 0.5 as the threshold for the slope, 19 of the 60 crossings were RDs, 8 by $\mathrm{C} 1$ and 11 by $\mathrm{C} 3$. As mentioned earlier, the sign of the Walén slope indicates whether a crossing occurred sunward or tailward of the reconnection site. Of the 19 RD crossings, 12 had positive Walén slopes, i.e. were sunward crossings, and 7 had negative slopes, i.e. were tailward crossings. Plotting the occurrence of positive and negative slopes versus the magnitude of the magnetic shear across the magnetopause (Fig. 13, bottom), one notices a strong asymmetry: cases with large shear have predominantly negative slopes, i.e. they occur tailward of the reconnection site, while lower shear crossings occur predominantly on the sunward side.

On the other hand, the magnitude of the Walen slopes is not correlated with magnetic shear, as demonstrated in Fig. 14a. The figure also shows that slopes $>0.5$ occur for shear angles $\geq 60^{\circ}$, except for one case where the shear is only $20^{\circ}$. To test whether the magnetopause thickness depends on its characterization as RD or TD, Fig. 14b plots the magnetopause thickness versus the Walén slope magnitude. No dependence is apparent.

If the magnetopause is a $\mathrm{TD}$, then there is no magnetic coupling across the magnetopause, and the HT frame should be well-anchored in the magnetosheath plasma, i.e. the difference between the magnetosheath velocity and the HT velocity should be small (e.g., Hasegawa et al., 2004b). If it is an RD, the opposite should hold, i.e. the difference between the magnetosheath velocity and the HT velocity should be large. In Fig. 14c we have plotted the magnitude of the difference, $\left|\mathbf{V}_{m s h}-\mathbf{V}_{H T}\right|$, between the magnetosheath and HT velocities versus the Walén slope. The figure shows that there is a clear trend, in the sense that the velocity difference becomes larger for larger slopes, confirming the effect of magnetic coupling.

\subsection{Boundary layer statistics}

For all 60 crossings by $\mathrm{C} 1$ and $\mathrm{C} 3$ we have determined whether a boundary layer was observed, by comparing the 0.2 -s resolution magnetic field and plasma density profiles. We found that 25 of the 60 crossings (i.e. $42 \%$ ) showed no sign of a boundary layer at the location of the crossing. Good examples are the crossings at 23:57 (Fig. 4), at 05:45 (Fig. 6), except for the $\mathrm{C} 3$ crossing, and 11:49 (Fig. 8). In our statistics, crossings without a trace of a boundary layer are referred to as Category 1.

The remaining 35 cases showed boundary layers of varying character or extent. When a thin boundary layer exists, one can estimate its thickness using the speed determined from the adjacent magnetopause crossing. An example is the 
05:45 crossing by C3. But for boundary layers with longer durations and/or irregular (e.g., non-monotonic) density profiles, a thickness definition and determination is difficult. To avoid this problem we have sorted all boundary layers into just three more categories. Category 2 are the cases with thin boundary layers. Category 3 comprises cases with a more extended boundary layer, with an initial sharp density drop at the magnetopause, followed by a medium-density (a few $\mathrm{cm}^{-3}$ ) boundary layer, often appearing as a density plateau. An example is the 15:26 crossing (Fig. 9). Finally, category 4 is for extended boundary layers without much drop at the magnetopause. The 11:00 UT crossing (Fig. 7) is such an example. In all Category 4 cases the boundary layer was actually the plasma mantle itself. Figure 15 shows the number of crossings versus the boundary layer category as just defined.

An interesting subset of the crossings without a boundary layer are those that were classified as RDs in the previous section. There are eight such cases. Because of the wedgeshape of the boundary layer resulting from reconnection, RDs should have a thickness near zero only when crossed close to the X-line, as already discussed in Sect. 5.3. But if this interpretation is correct, it follows that the observed local magnetic shear should also be representative of the magnetic shear at the $\mathrm{X}$ itself. Of the eight crossings in this category only three have large shear angles $\left(\geq 140^{\circ}\right)$. One case has a shear angle of $120^{\circ}$, and the remaining four have values $\leq 100^{\circ}$. In those cases the reconnecting fields are far from being anti-parallel.

If these eight crossings are indeed close to the $\mathrm{X}$-line, then it also follows that the Alfvén Mach number, $M_{A}$, in the adjoining magnetosheath should be representative of the $M_{A}$ at the X-line itself. It is thus highly significant that in all cases $M_{A}>1$, with values ranging from 1.2 to 2.1 . Of the 8 cases, two occurred on the tailward branch, and the other 6 on the sunward branch.

\section{Summary and conclusion}

We have analyzed all well-defined magnetopause crossings on a single Cluster orbit that skimmed the near-tail dawnside magnetopause at GSM local times between 5.0 and $3.8 \mathrm{~h}$ and GSM latitudes between $32^{\circ}$ and $4^{\circ}$. By including all crossings in a long sequence, subjective selections were avoided. The crossings are characterized by a stable magnetic field orientation on the magnetosphere side, but quite variable field directions on the magnetosheath side, giving rise to magnetic shear angles that ranged between $\sim 0^{\circ}$ and $\sim 180^{\circ}$. A magnetic signature was observed in all these crossings, usually both a field rotation and a change in field strength. The magnetopauses were well-resolved in the data. Even the shortest crossing included more than 20 magnetic field samples (at $0.2 \mathrm{~s}$ spacing). We obtained magnetopause orientation, speed, thickness, and currents from four-spacecraft analysis of 24 complete passes, i.e. for a total of 96 individual magnetopause crossings. There were other crossings that

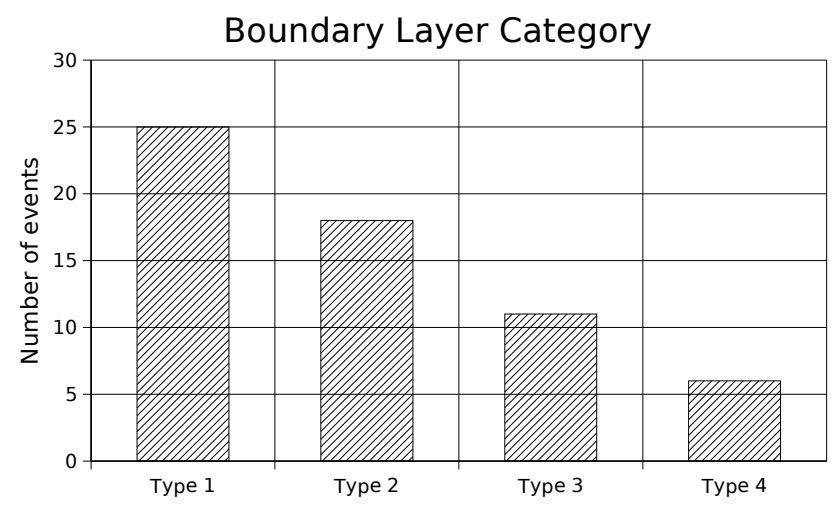

Fig. 15. Histogram of boundary layer classifications for the $C 1$ and C3 crossings. There are 25, 18, 11, and 6 crossings of types 1 (no boundary layer) to 4 (extended high density boundary layer), respectively.

involved fewer than four spacecraft, which were included in the single-spacecraft analysis of the TD/RD and boundary layer classifications. A total of $60 \mathrm{C} 1$ and $\mathrm{C} 3$ crossings were analyzed this way.

The main results may be summarized as follows:

Magnetopause thickness. Magnetopause current sheet thicknesses on this pass range from 100 to $2500 \mathrm{~km}$, but with the majority of the events having a thickness in the 400 to $800 \mathrm{~km}$ range, with an average of $\sim 750 \mathrm{~km}$. As already noted, these results are in agreement with the ISEE and AMPTE/IRM results (Berchem and Russell, 1982; Phan and Paschmann, 1996), although those were obtained for locations sunward of the dawn-dusk terminator, with local times ranging between 08 and $17 \mathrm{~h}$, while ours were taken at locations past the terminator, at local time times between 3.8 and $5.0 \mathrm{~h}$. The fact that the magnetopause thickness does not appear to systematically grow with distance from the subsolar point implies that the diffusion coefficient for the current is low.

Normalization to either to the magnetosheath ion gyroradius or ion inertial length did not alter this large dynamic range, because those characteristic lengths were fairly constant themselves, of the order of $50 \mathrm{~km}$. So one must conclude that the magnetopause thickness is not controlled by those characteristic scales. There also appears to be no correlation between magnetopause thickness and local magnetic shear angle, confirming the result of Berchem and Russell (1982). The thickness reduction for large $(>10)$ plasma- $\beta$ reported in the literature (Le and Russell, 1994; Phan and Paschmann, 1996) could not be checked because $\beta$ was $<2$ in our cases.

Note that the spacecraft separation distances impose some constraints for the multi-spacecraft methods. In order to traverse all four spacecraft, the amplitude of magnetopause motion needs to be larger than the spacecraft separation distances, i.e. $\sim 3000 \mathrm{~km}$ on this pass. Our results unavoidably contain this bias.

Magnetopause speed. Typical magnetopause speeds are 
20 to $80 \mathrm{~km} \mathrm{~s}^{-1}$, with extremal velocities up to $180 \mathrm{~km} \mathrm{~s}^{-1}$. The average velocity is $48 \mathrm{~km} \mathrm{~s}^{-1}$. This result is also in good agreement with the ISEE and AMPTE/IRM results.

Magnetopause orientation. Magnetopause orientations in general were consistent with expectations from a model magnetopause, but close pairs of inbound/outbound crossings showed systematic variations in tilt angles, indicative of the passage of surface waves.

Current density. Current densities range from $<0.01$ to $\sim 0.30 \mu \mathrm{A} \mathrm{m}^{-2}$, with an average of $0.05 \mathrm{uA}$. For those crossings with large shear, i.e. those with similarly large $\Delta B_{\max }$, the current densities were inversely proportional to magnetopause thickness, so that the total current was about the same, as required when the field change across the magnetopause remains constant.

Rotational versus tangential discontinuities. Based on tests of the Walén relation, 19 of the $60 \mathrm{C} 1$ and C 3 crossings could be classified as RDs, if one adopts a slope in excess of 0.5 as the RD criterion. The observation of plasma jetting lends credence to the identification of cases with Walén slopes of only 0.5 as RDs. The tendency for the difference between magnetosheath and HT velocities to increase with increasing Walén slope supports the notion that large Walén slopes are indicative of strong magnetic coupling across the magnetopause.

Of the 19 cases identified as RDs, 12 had postive Walén slopes and 7 had negative Walén slopes. There is an interesting asymmetry in the distribution of the cases with positive and negative Walén slope as a function of shear. The cases with large shear had predominantly negative slopes (i.e. were crossings tailward of the reconnection site, while lower shear cases all had positive slopes, i.e. were crossings sunward (and southward or northward, depending on the sign of the shear angle) of the reconnection site.

In none of the cases have we observed the actual passage of an X-line, i.e. a sign switch of the Walén slope in between spacecraft crossings. If all reconnection sites were created on the dayside magnetopause and stayed there, then only negative slopes should have been observed. The cases with a positive slope could mean (a) that the $\mathrm{X}$-line, although having been formed further sunward, had moved past the spacecraft location by the time those crossings occurred; or (b) that those X-lines were already located tailward of Cluster when they were formed. It is the flow speed relative to the Alfvén speed in the magnetosheath at the reconnection site that should determine whether the X-line is stationary or moves (e.g., La Belle-Hamer et al., 1995). But without knowledge of the conditions at the X-line one cannot tell. As we will argue below, the subset of RDs without a boundary layer can provide this knowledge.

Boundary Layer. Our analysis has found that 26 of the 60 individual $\mathrm{C} 1$ and $\mathrm{C} 3$ crossings show no trace of a boundary layer, thus confirming earlier ISEE results (Sckopke et al., 1981) that the dawn flank LLBL thickness is highly variable. Our results do not confirm the conclusion of Mitchell et al. (1987), based on ISEE data as well, that the LLBL becomes thicker with increasing distance from the subsolar point. The only crossings we observed having a substantial boundary layer are actually not crossings into the LLBL, but into the plasma mantle. Of the 26 crossings without boundary layer, 8 were identified as RDs.

Magnetopause crossings without a boundary layer have been reported earlier. Papamastorakis et al. (1984) discussed a low-latitude dayside crossing by ISEE-1 and -2 with large magnetic shear that showed no sign of an LLBL, in spite of adequate time resolution of the data. That crossing was identified as a TD, based on the failure to satisfy the jump conditions for an RD. Gosling et al. (1986) have analyzed ISEE crossings of the near-tail dusk magnetopause and found a large number of accelerated flow events, i.e. crossings tailward of an X-line, without evidence for a boundary layer. Their crossings were characterized by almost antiparallel fields (nearly $180^{\circ}$ shear). The evidence for crossings on the sunward side of the $\mathrm{X}$ was not so clear. Interestingly, Gosling et al. (1986) report that accelerated flow events are much rarer among the ISEE crossings of the near-tail dawn magnetopause, where our measurements were made. They speculated that this asymmetry might be explained in terms of a combined latitude-seasonal effect in the ISEE sampling of the near-tail dusk and dawn magnetopause.

From a statistical analysis of ISEE-2 and AMPTE/CCE data, Eastman et al. (1996) concluded that nearly $10 \%$ of the crossings, which included the dawn and dusk flanks, exhibited no trace of a boundary layer. Eastman et al. suggested that the lack of a boundary layer indicated that these were crossings close to an X-line, although they did not actually know whether the crossings were RDs. The eight RD cases without a boundary layer that we have found would fit this picture. But if these indeed are crossings close to an $\mathrm{X}$-line, then one should expect the observed magnetic shear and Alfvén Mach number to be representative of the conditions at the $\mathrm{X}$-line itself. It is therefore interesting that four of the eight cases had shear angles $\leq 100^{\circ}$, i.e. the magnetic fields were far from being anti-parallel. If the interpretation of these cases as crossings close to the X-line is correct, their magnetic shear would thus be inconsistent with the anti-parallel reconnection hypothesis. Furthermore, all eight cases had Alfvén Mach numbers $M_{A}>1$ in the adjoining magnetosheath, a situation where, according to conventional wisdom, the reconnection site (the X-line) cannot sit still. So if those crossings did indeed occur close to an Xline, the X-line was probably moving tailward rapidly.

A final point concerns the crossings without a boundary layer that are not RDs but TDs. To observe TDs with no boundary layer at such large distances from the subsolar point appears to rule out diffusion over large portions of the magnetopause as an effective means for plasma transport across the magnetopause.

\section{Appendix A}

In this appendix, a brief summary is presented of previously existing multi-spacecraft methods for determination of 
magnetopause orientation, motion, and thickness. Also, the new method (MTV) applied in this paper is described in detail.

Assume that the instantaneous magnetopause velocity is expressed by:

$V(t)=A_{0}+A_{1} t+A_{2} t^{2}+A_{3} t^{3}$,

where $A_{0}, A_{1}, A_{2}$, and $A_{3}$ are constants to be determined from the crossing times and durations. With the above expression for $\mathrm{V}(\mathrm{t})$, we find the magnetopause thicknesses, $d_{i}$ $(i=0,1,2,3)$, to be

$$
\begin{aligned}
d_{i} & =\int_{t_{i}-\tau_{i}}^{t_{i}+\tau_{i}} V(t) d t \\
& =2 \tau_{i}\left[V\left(t_{i}\right)+\left(A_{2} \tau_{i}^{2}\right) / 3+A_{3} t_{i} \tau_{i}^{2}\right] .
\end{aligned}
$$

The center crossing times, $t_{i}$, where $t_{3}>t_{2}>t_{1}>t_{0}$, and corresponding crossing durations, $\tau_{i}$, are considered as known quantities. The distance travelled by the magnetopause, between crossing $\mathrm{CR}_{i}$ and crossing $\mathrm{CR}_{0}$ (not to be confused with the Cluster spacecraft naming convention; C1...C4) along a fixed normal direction, $\mathbf{n}$, is then

$$
\begin{aligned}
\mathbf{R}_{i} \cdot \mathbf{n} & =\int_{t=0}^{t=t_{i}} V(t) d t \\
& =A_{0} t_{i}+\frac{A_{1} t_{i}^{2}}{2}+\frac{A_{2} t_{i}^{3}}{3}+\frac{A_{3} t_{i}^{4}}{4}
\end{aligned}
$$

where $\mathrm{CR}_{i}$ is relative to that producing $\mathrm{CR}_{0}$.

In the Constant Velocity Approach (CVA), the coefficients $A_{1}, A_{2}$, and $A_{3}$ are put to zero so that $A_{0}$ becomes the constant, but unknown velocity. The three Eqs. (A3) can then be solved for the vector $\mathbf{m}=\mathbf{n} / A_{0}$, and $A_{0}$ can be obtained from the normalization $|\mathbf{n}|^{2}=1$.

In the Constant Thickness Approach (CTA), the thicknesses $d_{i}$ are assumed the same, $d_{i}=d$ for $\mathrm{i}=0,1,2,3$. The four Eqs. (A2) can then be solved for the four quantities $A_{0} / d, A_{1} / d, A_{2} / d$ and $A_{3} / d$ and, subsequently, the three Eqs. (A3) for the vector $\mathbf{m}=\mathbf{n} / d$. Finally, the thickness $d$ is obtained from the normalization of $\mathbf{n}$.

In the Discontinuity Analyzer (DA) approach, the normal direction is taken from some single-spacecraft method, such as minimum variance analysis of the magnetic field (MVAB) or minimum Faraday residue (MFR) analysis (Khrabrov and Sonnerup, 1998). Equations (A3) can then be solved for the coefficients $A_{0}, A_{1}$, and $A_{2}$ but $A_{3}$ must be put to zero. The DA approach is not a pure multi-spacecraft timing method because it makes use of a normal vector obtained from single-spacecraft data analysis. It has the advantage that it permits both velocity and thickness of the magnetopause to vary from crossing to crossing in an event. Its disadvantage is that the velocity polynomial in equation (A1) becomes quadratic rather than cubic, which is less flexible and can more easily lead to unreasonable results. Detailed illustrations of CVA, CTA, and DA (in the version decribed here), have been given by Haaland et al. (2004) for one of the 5 July 2001, magnetopause crossings (at 06:23 UT).

The new MTV method is a combination of CVA, CTA, and DA, but uses no single-spacecraft methods and produces a cubic velocity polynomial. In the MTV method, the normal vector is obtained as a combination of the two normal vectors obtained from CVA and CTA, which are usually not the same (if they are the same, then the crossing has both constant velocity and constant thickness). In the body of this paper the combination of the two normal vectors is taken to be their renormalized average but there may be circumstances where it is justified to place more emphasis on one normal than on the other. Once the combined normal is known, the MTV method uses DA, i.e. Eq. (A3), to provide three of the four equations needed to determine the velocity coefficients $A_{\ldots} A_{3}$. Rather than putting $A_{3}=0$, a fourth equation is obtained from the subsidiary condition that the variance of the thicknesses seen at the four spacecraft should be a minimum. This condition is again not unique. It is motivated by the argument that the thickness variations are expected to be much smaller than the velocity variations during a typical event. The algebraic details of the MTV method are as follows:

The average thickness seen by the four spacecraft is

$$
\langle d\rangle=\frac{1}{4} \sum_{i=0}^{i=3} d_{i},
$$

where the expressions for $d_{i}$ are given by Eq. (A3). The variance in thickness can be written as

$$
\sigma^{2}=\frac{1}{4} \sum_{i=0}^{i=3}\left[d_{i}-\langle d\rangle\right]^{2}=\left\langle d_{i}^{2}\right\rangle-\left\langle d_{i}\right\rangle^{2}
$$

which is a quadratic form in the coefficients $A_{0} \ldots A_{3}$. The minimization of this form with respect to $A_{0}$, say, is written as

$$
\frac{d}{d A_{0}} \sigma^{2}=0
$$

In performing the differentiation, one must remember that the four velocity coefficients $A_{0} \ldots A_{3}$ are interrelated via the three Eqs. (A3). The derivatives $d A_{1} / d A_{0}, d A_{2} / d A_{0}$, and $d A_{3} / d A_{0}$ can be obtained by differentiation of those three equations. When the expressions for these derivatives are substituted into Eq. (A6), one obtains, after considerable algebra, the following linear relationship

$K_{0} A_{0}+K_{1} A_{1}+K_{2} A_{2}+K_{3} A_{3}=0$,

which can be used together with the three equations (A3) to provide four linear equations for the four velocity coefficients $A_{0} \ldots A_{3}$. The constants $K_{0} \ldots K_{3}$ in Eq. (A7) are given by

$$
\begin{aligned}
K_{0} & =\frac{\Delta\langle T \tau\rangle}{\langle T\rangle} \\
K_{1} & =\frac{\Delta\langle T \tau t\rangle}{\langle T\rangle}
\end{aligned}
$$




$$
\begin{aligned}
K_{2} & =\frac{\left[\Delta\left\langle T \tau t^{2}\right\rangle+1 / 3 \Delta\left\langle T \tau^{3}\right\rangle\right]}{\langle T\rangle} \\
K_{3} & =\frac{\left[\Delta\left\langle T \tau t^{3}\right\rangle \Delta\left\langle T \tau^{3} t\right\rangle\right]}{\langle T\rangle}
\end{aligned}
$$

where the following notation has been used:

$$
\begin{aligned}
\Delta\langle T \tau\rangle & =\langle T \tau\rangle-\langle T\rangle\langle\tau\rangle \\
\Delta\langle T \tau t\rangle & =\langle T \tau t\rangle-\langle T\rangle\langle\tau t\rangle \\
\Delta\left\langle T \tau t^{2}\right\rangle & =\left\langle T \tau t^{2}\right\rangle-\langle T\rangle\left\langle\tau t^{2}\right\rangle \\
\ldots & =\ldots,
\end{aligned}
$$

The times $\mathrm{T}$ represent the four expressions

$$
\begin{aligned}
T_{i} & =\tau_{i}\left[1-2 t_{i}\left(1 / t_{1}+1 / t_{2}+1 / t_{3}\right)\right. \\
& +3\left(t_{i}^{2}+(1 / 3) \tau_{i}^{2}\right)\left(1 / t_{1} t_{2}+1 / t_{1} t_{3}+1 / t_{2} t_{3}\right) \\
& \left.-4\left(t_{i}^{3}+t_{i} \tau_{i}^{2}\right) / t_{1} t_{2} t_{3}\right],
\end{aligned}
$$

where $t_{i}=0, t_{1}, t_{2}, t_{3}$ are the crossing times. The average value of $\mathrm{T}$ is $\langle T\rangle=\left(T_{0}+T_{1}+T_{2}+T_{3}\right) / 4$; other averages are similarly denoted.

Although the procedure described here is not unique, and may appear complicated, it has the advantage of producing a single answer, rather than separate answers from CVA and CTA. It is based entirely on multi-spacecraft timing and avoids the pitfalls associated with the use of singlespacecraft methods for obtaining the vector normal to the magnetopause. For individual events, it may not always be optimal but it is convenient for statistical studies of the kind presented in this paper. Finally, if single-spacecraft analysis provides normal vectors from the four spececraft that are consistent and of high quality, then the MTV concept can be used to produce a cubic, rather than quadratic, velocity profile for DA.

Acknowledgements. This work was supported byDeutsches Zentrum für Luft- und Raumfahrt (DLR) under grant 50 OC 01. Research at Dartmouth College was supported by the National Aeronautics and Space Administration under grant NAG5-12005. Parts of the data analysis were done with the Queen Mary, University of London, Science Analysis System for Cluster (QSAS).

Topical Editor T. Pulkkinen thanks V. Semenor and another referee for their help in evaluating this paper.

\section{References}

Balogh, A., Dunlop, M. W., Cowley, S. W. H., Southwood, D. J., Thomlinson, J. G., Glassmeier, K. H., Musmann, G., Luhr, H., Buchert, S., Acuna, M. H., Fairfield, D. H., Slavin, J. A., Riedler, W., Schwingenschuh, K., and Kivelson, M. G.: The Cluster Magnetic Field Investigation, Space Science Reviews, 79, 65-91, 1997.

Berchem, J. and Russell, C. T.: The thickness of the magnetopause current layer - ISEE 1 and 2 observations, J. Geophys. Res., 87, 2108-2114, 1982.

Berchem, J. and Russell, C. T.: Magnetic field rotation through the magnetopause - ISEE 1 and 2 observations, J. Geophys. Res., 87, 8139-8148, 1982.
Eastman, T. E., Fuselier, S. A., and Gosling, J. T.: Magnetopause crossings without a boundary layer, J. Geophys. Res., 101, 49$58,1996$.

Elphic, R. C. and Russell, C. T.: ISEE-1 and -2 magnetometer observations of the magnetopause, in Magnetospheric Boundary Layers, edited by B. Battrick, ESA SP-148, p. 43, ESA Publications Division, Paris, 1979.

Gosling, J. T., Thomsen, M. F., Bame, S. J., and Russell, C. T.: Accelerated plasma flows at the near-tail magnetopause, J. Geophys. Res., 91, 3029-3041, 1986.

Gustafsson, G., Boström, R., Holbäck, B., Holmgren, G., Lundgren, A., Stasiewicz, K., Ahlen, L., Mozer, F. S., Pankow, D., Harvey, P., Berg, P., Ulrich, R., Pedersen, A., Schmidt, R., Butler, A., Fransen, A. W. C., Klinge, D., Thomsen, M., Fälthammar, C.G., Lindqvist, P.-A., Christenson, S., Holtet, J., Lybekk, B., Sten, T. A., Tanskanen, P., Lappalainen, K., and Wygant, J.: The Electric Field and Wave Experiment for the Cluster Mission, Space Sci. Rev., 79, 137-156, 1997.

Haaland, S., Sonnerup, B. U. Ö., Dunlop, M. W., Balogh, A., Hasegawa, H., Klecker, B., Paschmann, G., Lavraud, B., Dandouras, I., and Rème, H.: Four-Spacecraft Determination of Magnetopause Orientation, Motion and Thickness: Comparison with Results from Single-Spacecraft Methods, Ann. Geophys., 22, 1347-1365, 2004.

Harris, E. G.: On the plasma sheath separating regions of oppositely directed magnetic field., Nuovo Cimento, 23, 115-121, 1962.

Hasegawa, H., Sonnerup, B. U. Ö., Dunlop, M. W., Balogh, A., Haaland, S. E., Klecker, B., Paschmann, G., Lavraud, B., Dandouras, I., and Rème, H.: Reconstruction of two-dimensional magnetopause structures from Cluster observations: Verification of method, Ann. Geophys., 22, 1251-1266, 2004a.

Hasegawa, H., Sonnerup, B. U. Ö., Klecker, B., Paschmann, G., Dunlop, M. W., Balogh, A., and Rème, H.: Optimal reconstruction of magnetopause structures from Cluster data, Ann. Geophys., 23, 973-982, 2004b.

Khrabrov, A. V. and Sonnerup, B. U. Ö.: Orientation and motion of current layers: Minimization of the Faraday residue, Geophys. Res. Let., 25, 2373-2376, 1998a.

Khrabrov, A. V. and Sonnerup, B. U. Ö.: DeHoffmann-Teller Analysis, in Analysis Methods for Multi-Spacecraft Data, edited by G. Paschmann and P. W. Daly, ISSI SR-001, p. 221, ESA Publications Division, 1998b.

La Belle-Hamer, A. L., Otto, A., and Lee, L. C.: Magnetic reconnection in the presence of sheared flow and density asymmetry: Applications to the Earth's magnetopause, J. Geophys. Res., 100, $11875-, 1995$.

Le, G. and Russell, C. T.: The thickness and structure of high beta magnetopause current layer, Geophys. Res. Let., 21, 2451-2454, 1994.

Levy, R. H., Petschek, H. E., and Siscoe, G. L.: Aerodynamic aspects of the magnetospheric flow, AIAA Journal, 2, 2065, 1964.

Mitchell, D. G., Kutchko, F., Williams, D. J., Eastman, T. E., Frank, L. A., and Russell, C. T.: An extended study of the low-latitude boundary layer on the dawn and dusk flanks of the magnetosphere, J. Geophys. Res., 92, 7394-7404, 1987.

Papamastorakis, I., Paschmann, G., Sckopke, N., Bame, S. J., and Berchem, J.: The magnetopause as a tangential discontinuity for large field rotation angles, J. Geophys. Res., 89, 127-135, 1984.

Paschmann, G., Baumjohann, W., Sckopke, N., Papamastorakis, I., and Carlson, C. W.: The magnetopause for large magnetic shear - AMPTE/IRM observations, J. Geophys. Res., 91, 11 099$11115,1986$. 
Phan, T.-D. and Paschmann, G.: Low-latitude dayside magnetopause and boundary layer for high magnetic shear 1. Structure and motion, J. Geophys. Res., 101, 7801-7816, 1996.

Phan, T.-D., Paschmann, G., and Sonnerup, B. U. Ö.: Low-latitude dayside magnetopause and boundary layer for high magnetic shear 2. Occurrence of magnetic reconnection, J. Geophys. Res., 101, 7817-7828, 1996.

Rème, H., Aoustin, C., Bosqued, J. M., Dandouras, I., Lavraud, B., Sauvaud, J. A., Barthe, A., Bouyssou, J., Camus, T., CoeurJoly, O., Cros, A., Cuvilo, J., Ducay, F., Garbarowitz, Y., Medale, J. L., Penou, E., Perrier, H., Romefort, D., Rouzaud, J., Alcayde, D., Jacquey, C., Mazelle, C., d'Uston, C., Möbius, E., Kistler, L. M., Crocker, K., Granoff, M., Mouikis, C., Popecki, M., Vosbury, M., Klecker, B., Hovestadt, D., Kucharek, H., Kuenneth, E., Paschmann, G., Scholer, M., Sckopke, N., Seidenschwang, E., Carlson, C. W., Curtis, D. W., Ingraham, C., Lin, R. P., McFadden, J. P., Parks, G. K., Phan, T., Formisano, V., Amata, E., Bavassano-Cattaneo, M. B., Baldetti, P., Bruno, R., Chioncho, G., Lellis, A. D., Marcucci, M. F., Pallochia, G., Korth, A., Daly, P. W., Graeve, B., Rosenbauer, H., Vasyliunas, V., McCarthy, M., Wilber, M., Eliasson, L., Lundin, R., Olsen, S., Shelley, E. G., Fuselier, S., Ghielmetti, A. G., Lennartsson, W., Escoubet, C. P., Balsiger, H., Friedel, R., Cao, J.-B., Kovrazhkin, R. A., Papamastorakis, I., Pellat, R., Scudder, J., and Sonnerup, B. U. Ö.: First multispacecraft ion measurements in and near the Earth's magnetosphere with the identical Cluster ion spectrometry (CIS) experiment, Ann. Geophys., 19, 1303-1354, 2001.

Robert, P., Dunlop, M. W., Roux, A., and Chanteur, G.: Accuracy of Current Density Determination, in Analysis Methods for MultiSpacecraft Data, edited by G. Paschmann and P. W. Daly, ISSI SR-001, p. 395, ESA Publications Division, 1998.

Rosenbauer, H., Grünwaldt, H., Montgomery, M. D., Paschmann, G., and Sckopke, N.: Heos 2 plasma observations in the distant polar magnetosphere - The plasma mantle, J. Geophys. Res., 80, 2723-2737, 1975.
Russell, C. T., Mellott, M. M., Smith, E. J., and King, J. H.: Multiple spacecraft observations of interplanetary shocks: Four spacecraft determination of shock normals, J. Geophys. Res., 88, 4739-4748, 1983.

Schwartz, S. J.: Shock and Discontinuity Normals, Mach Numbers, and Related Parameters, in Analysis Methods for MultiSpacecraft Data, edited by G. Paschmann and P. W. Daly, ISSI SR-001, 249-270, ESA Publications Division, 1998.

Sckopke, N., Paschmann, G., Haerendel, G., Sonnerup, B. U. O., Bame, S. J., Forbes, T. G., Hones, E. W., and Russell, C. T.: Structure of the low-latitude boundary layer, J. Geophys. Res., 86, 2099-2110, 1981.

Scudder, J. D., Puhl-Quinn, P. A., Mozer, F. S., Ogilvie, K. W., and Russell, C. T.: Generalized Walén tests through Alfvén waves and rotational discontinuities using electron flow velocities, J. Geophys. Res., 104, 19817-19 834, 1999.

Song, P., Russell, C. T., Fitzenreiter, R. J., Gosling, J. T., Thomsen, M. F., Mitchell, D. G., Fuselier, S. A., Parks, G. K., Anderson, R. R., and Hubert, D.: Structure and properties of the subsolar magnetopause for northward interplanetary magnetic field: Multiple-instrument particle observations, J. Geophys. Res., 98, 11319-11337, 1993.

Sonnerup, B. U. Ö. and Scheible, M.: Minimum and Maximum Variance Analysis, in Analysis Methods for Multi-Spacecraft Data, edited by G. Paschmann and P. W. Daly, ISSI SR-001, 1850, ESA Publications Division, 1998.

Sonnerup, B. U. Ö., Paschmann, G., Papamastorakis, I., Sckopke, N., Haerendel, G., Bame, S. J., Asbridge, J. R., Gosling, J. T., and Russell, C. T.: Evidence for magnetic field reconnection at the earth's magnetopause, J. Geophys. Res., 86, 10 049-10 067, 1981.

Sonnerup, B. U. Ö., Papamastorakis, I., Paschmann, G., and Lühr, H.: The magnetopause for large magnetic shear: Analysis of convection electric fields from AMPTE/IRM, J. Geophys. Res., 95, 10 541-10 557, 1990. 